\title{
Influence of Loose Contact between Tunnel Lining and Surrounding Rock on the Safety of the Tunnel Structure
}

\author{
Zijian Ye ${ }^{1,2}$ and Chengping Zhang ${ }^{1,2, *}$ \\ 1 Key Laboratory of Urban Underground Engineering of Ministry of Education, Beijing Jiaotong University, \\ Beijing 100044, China; 17115306@bjtu.edu.cn \\ 2 School of Civil Engineering, Beijing Jiaotong University, Beijing 100044, China \\ * Correspondence: chpzhang@bjtu.edu.cn
}

Received: 15 September 2020; Accepted: 16 October 2020; Published: 20 October 2020

\begin{abstract}
The improvement of the contact state between the surrounding rock and tunnel lining, such as the effect of back-fill grouting behind lining, was important for maintaining the stability of the lining structure. To explore the influence of loose contact states behind lining on the safety of tunnel lining, a case of field investigation in a railway tunnel with a symmetrical lining structure was presented in this paper. A model test was conducted to prove the accuracy of the numerical simulation in the condition of dense contact state between the lining and surrounding rocks. Based on this, the three-dimensional (3-D) impact of loose contact states on the mechanic behavior of the lining structure under different compactness and different loose contact areas behind lining was investigated and summarized. Furthermore, the influence of the percentage of the insufficient strength behind lining was explored. Finally, the grade of the influence of the loose contact state on the safety of the lining structure was classified. The results revealed that: (1) in order to maintain the stability of lining structure, the compactness of the back-fill grouting behind lining was recommended to be above $80 \%$, and the range of the loose contact area should be no more than 60 degree; (2) the strength of the back-fill grouting behind lining should be above $50 \%$ strength of the surrounding rock, the loose contact state behind lining should be improved in time to avoid expansion of the loose contact area; and (3) the classification of the influence grade on the safety of the lining structure provides a basic reference for controlling the quality of the back-fill grouting. This research gives a new point of view for the evaluation of the contact state between lining and surrounding rock.
\end{abstract}

Keywords: contact state; lining structure; railway tunnel; loose contact; back-fill grouting

\section{Introduction}

Nowadays, a large number of tunnels have been built. Take China as an example, the total number of the operational transportation tunnels had grown up to 19,067 with the overall length of 19 million meters until 2019 [1]. Over time, most of those tunnels have been in service for many years. However, poor construction, ground water erosion, and improper backfilling resulted in bad contact states between lining structure and surrounding rock, such as voids behind tunnel lining [2]. The existence of voids behind lining left a potential safety hazard for tunnel operation. Eccentric loading and redistribution of earth pressure on the lining structure can cause cracks of the lining structure [3-8].

Effective contact between the lining structure and surrounding rock plays an important role in exerting the bearing capacity of the structure, and ensuring the safe and stable operation of the tunnel [9-13]. At present, there are lot of studies on the cavities or voids behind tunnel lining. 
The elastic-plastic finite element analysis was used to explore the influence of different sizes, locations, and depths of voids on the deformation and stress redistribution of lining [2,14,15]. Three-dimensional (3-D) numerical analysis was adopted in erosion voids behind the walls in an existing sewer pipe, or circular tunnel [16-18]. Model tests were performed to evaluate the mechanical behavior of the lining structure and surrounding rock under the effect of local contact loss [19-22]. Moreover, various non-destructive testing (NDT) methods were applied to evaluate the lining quality [23-27]. Meanwhile, tunnel face stability analysis was fully investigated for the safety of tunnel construction [28-32].

However, most of these studies were limited to the assumption that the lining structure was not in contact completely with the surrounding rock in the study of voids behind lining. In the actual engineering project, the contact states between the lining structure and surrounding rock are complicated and changed with time. Due to the action of groundwater, improper excavation, and insufficient back-fill grouting behind lining, etc., the small voids left behind lining make the lining structures loosely or partly contacted with surrounding rock, as shown in Figure 1, in most cases [33]. Meanwhile, there has been no study on the evaluation of the effect of back-fill grouting after the treatment of voids behind lining recently. Whether the compactness or insufficient strength of the back-fill grouting area behind lining had impact on the safety of the lining structure should be questioned. Therefore, as one of the bad contact states behind lining, the influence of loose contact between the tunnel lining and surrounding rock on the safety of the railway tunnel should be investigated.
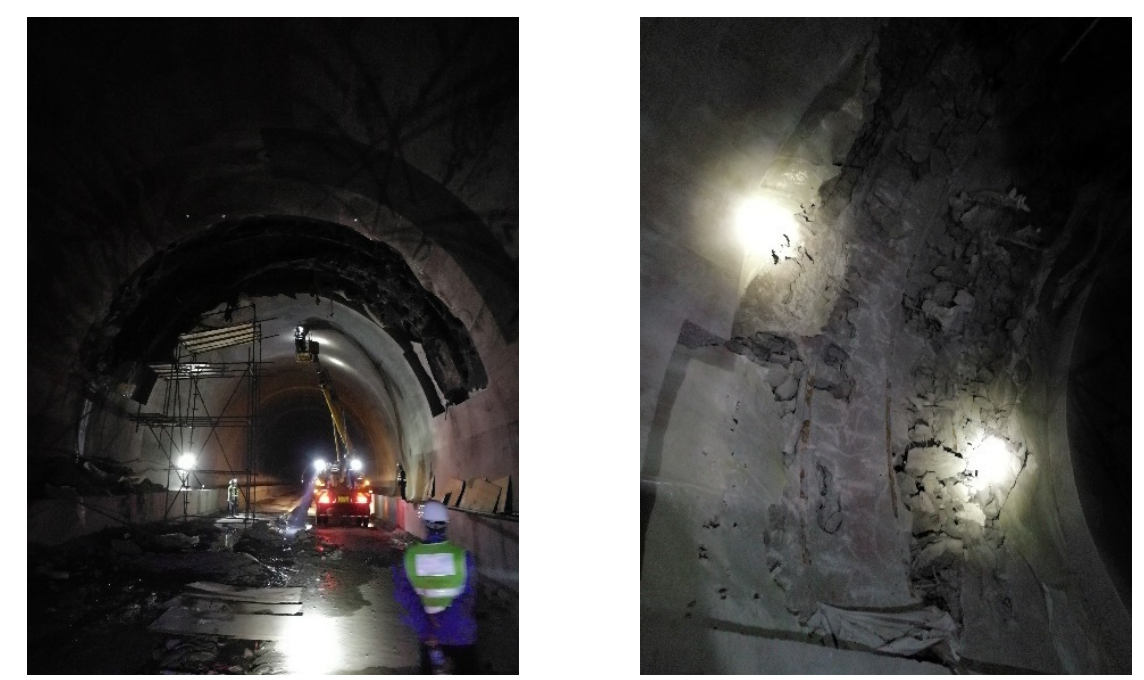

Figure 1. The lining structure needs to be repaired due to loose contact with surrounding rock.

To more accurately judge the stress state of the lining structure under loose contact with surrounding rock, and provide more comprehensive reference for the safety evaluation of lining structure, based on the field investigation in a railway tunnel in Sichuan Province in China, the elasto-plastic finite element analyses were adopted to investigate the 3-D effects of the loose contact developing behind lining on the safety of the tunnel in this paper. At first, the influence of the compactness and area of loose contact behind the lining on the mechanic behavior of the lining structure was explored. Then, the effect of insufficient strength behind the lining was studied as well. Variation laws of the mechanical behavior of the lining structure that under the impact of loose contact, including internal force of lining structure, contact pressure between lining structure, and deformation characteristic of lining structure, were summarized. At last, the effect of the compactness and insufficient strength of the loose contact area on the safety of lining was compared. In order to conveniently apply the research results in the back-fill grouting behind lining, the grade of the influence of loose contact on the safety of the lining structure was classified. This study can provide a reference for the evaluation of the contact state between tunnel lining and surrounding rock. 


\section{Field Investigation}

A double-line railway tunnel located in Sichuan Province in southwest China was selected as the study object [25]. The conventional drilling and blasting method was used in the construction of the tunnel. After the drilling and blasting, surrounding rocks were supported by the composite lining. The tunnel was supported with almost $0.1 \mathrm{~m}$ thick shotcrete at first, then the tunnel was supported by a cast-in-place reinforced concrete lining [14]. Due to the appearance of cracks on the surface of the lining structure, quality evaluation of the lining structure was conducted to maintain the safety of the tunnel structure. However, not only the cavities were found behind the lining structure, but also loose contact between the lining structure and surrounding rock was discovered. An imperfect contact status between the lining structure and surrounding rock threatened the safety of the tunnel operation. Therefore, to study the influence of imperfect contact between the lining structure and surrounding rock on the safety of the lining structure, the DK553+418-DK553+434 section of the tunnel was selected as the research object. The test section was classified as grade $\mathrm{V}$ in the Chinese code for designing railway tunnels [34], which means the surrounding rock interbedded with soft and hard rocks and had a relatively complete rock mass. The Classification of loose contact between lining structure and surrounding rock are shown in Table 1, and the main parameters of the surrounding rock are shown in Table 2. Th concrete lining had a compressive strength of $30 \mathrm{MPa}$. The thickness of the primary lining was designed to be $0.15 \mathrm{~m}$ and the secondary lining thickness was designed to be $0.5 \mathrm{~m}$.

Table 1. Classification of loose contact between lining structure and surrounding rock.

\begin{tabular}{ccccc}
\hline Category & $\begin{array}{c}\text { Back-Fill Grouting, or Natural } \\
\text { Filling Inside the Loose Area }\end{array}$ & Cause & $\begin{array}{c}\text { Characteristics of } \\
\text { the Loose Area }\end{array}$ & Influence Factor \\
\hline I & Loose (rock or grouting material) & $\begin{array}{c}\text { Back-fill grouting, or } \\
\text { natural filling } \\
\text { not compacted } \\
\text { Corrosion and erosion in } \\
\text { water-rich environment }\end{array}$ & $\begin{array}{c}\text { Many small voids } \\
\text { Insufficient } \\
\text { strength/soft }\end{array}$ & $\begin{array}{c}\text { Compactness of the } \\
\text { loose area }\end{array}$ \\
II & Soft (rock or grouting material) & $\begin{array}{c}\text { Strength parameters of } \\
\text { rock in the loose area }\end{array}$ \\
\hline
\end{tabular}

Table 2. Mechanical parameters of prototype materials.

\begin{tabular}{|c|c|c|c|c|c|}
\hline Cases & $\begin{array}{l}\text { Unit Weight } \\
\left(\mathrm{kN} / \mathrm{m}^{3}\right)\end{array}$ & $\begin{array}{l}\text { Elastic Modulus } \\
\quad \text { (GPa) }\end{array}$ & Poisson's Ratio & $\begin{array}{l}\text { Cohesive } \\
\text { Force (kPa) }\end{array}$ & Friction Angle $\left({ }^{\circ}\right)$ \\
\hline Surrounding rock & 18 & 1.5 & 0.4 & 100 & 24 \\
\hline Lining structure & 25 & 30 & 0.2 & / & 1 \\
\hline
\end{tabular}

Field investigation and GPR test results are shown in Figure 2. To ensure the GPR antenna has good contact with the tunnel lining surface, the detection vehicle with a platform was required to move forward smoothly at a speed of $23 \mathrm{~km} / \mathrm{h}$ during the inspection. The ground within the driving route of the detection vehicle on the survey line must be leveled before the detection. The cracks were found to be located on the sidewall and haunch of the lining. The location of the loose contact state behind lining could be recognized in the GPR test image. The propagation velocity of the electromagnetic wave in surrounding rock was characterized by the dielectric permittivity and magnetic permeability of the medium [35]. The propagation velocity was calibrated at the tunnel entrance, a position known to the lining thickness [25]. Then, the drilling test was conducted to verify the results, and a coring machine, air gun, and other tools were used during the test. After measuring the liner thickness, based on the experience of workers and the rotation speed of the drilling machine that drilled into rocks behind the lining, the contact state between the lining structure and surrounding rock could be distinguished. Different from the cavities, as shown in the section of DK553+424-DK553+431, the contact status was loosely in the section of DK553+418-DK553+423. It can be concluded that there were many small voids or uncompacted rock existing behind the lining structure, which made the lining structure not closely contacted with the surrounding rock. 


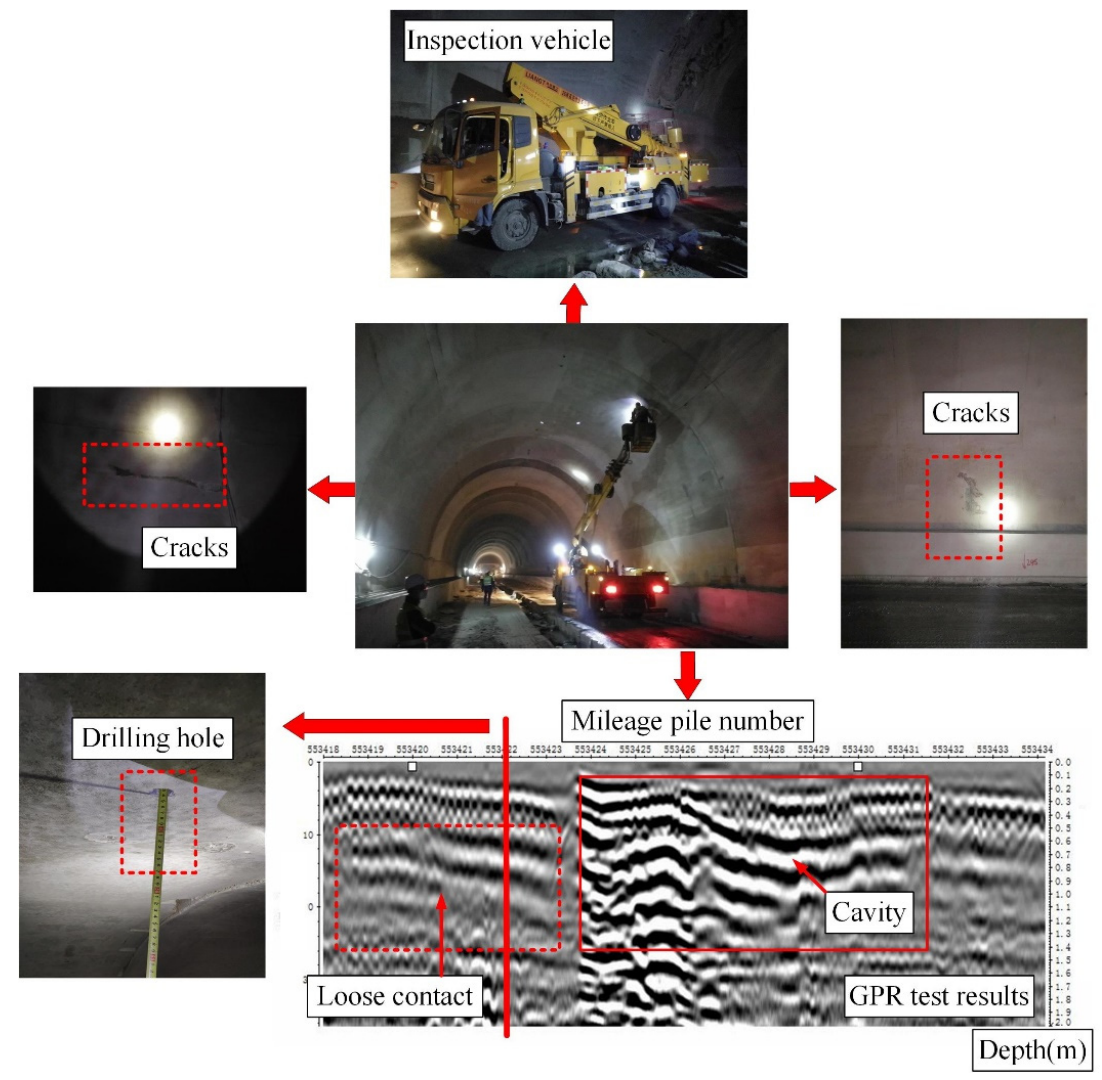

Figure 2. Field investigation.

Bad contact between the tunnel lining and surrounding rock usually exists mainly due to over-excavation before the lining construction, uneven surface of surrounding rock after drilling and blasting, improperly cast concrete lining, concrete shrinkage, etc. For the problem of loose contact between lining and surrounding rock, according to the field investigation and cause analysis, as shown in Table 1, the loose contact status can be classified into two categories.

The first one was the situation of insufficient compactness behind lining, as shown in Figure 3a. Unlike the large non-contacted area in the condition of cavities behind lining, due to construction problems, such as insufficient thickness of the primary and secondary lining, unproperly shotcrete etc., there were many voids left between the lining structure and surrounding rock. Therefore, to simulate small voids inside the loose area behind tunnel lining, the compactness of the loose area was selected as one of the parameters. Amounts of small voids could be reflected by the percentage of the compactness in the simulation.

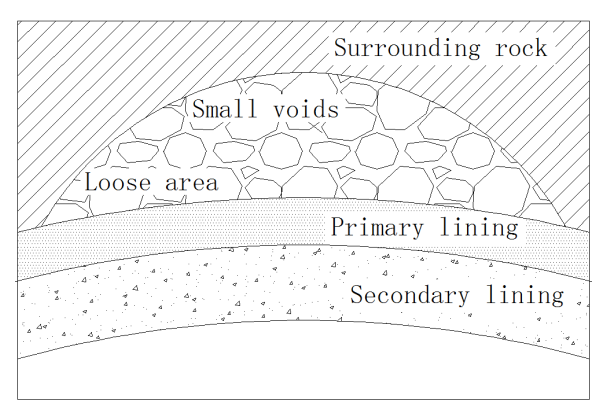

(a)

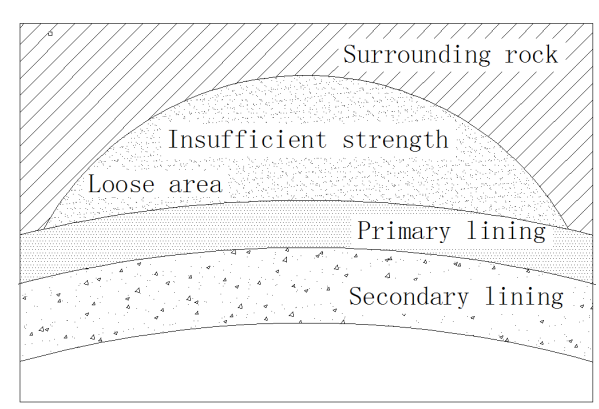

(b)

Figure 3. Simplified cause classification diagram. (a) I, (b) II. 
The second one was the situation of insufficient strength behind lining, as shown in Figure 3b. The strength of surrounding rock or grouting behind the lining was decreased gradually, mainly due to: (1) the surrounding rock or back-fill grouting behind the lining may contain substances that were easily dissolved or corroded during the tunnel operation; (2) under a water-rich environment or the presence of other chemicals, with the action of corrosion or erosion, or even in high temperature and low relative humidity [36]. The contact status between the lining structure and surrounding rock became loosely finally. Therefore, the loose area behind lining could be simulated by reducing the parameters of rock $[37,38]$.

\section{Numerical Simulation and Model Test Verification}

\subsection{Numerical Model}

The Abaqus v6.14-1 (Dassault Systèmes, Providence, RI, USA) was used to numerically analyze the influence of the contact status behind the lining on the safety of the lining structure. The tunnel geometry used in the numerical simulations is shown in Figure 4. Based on the classification of the loose contact status in Table 1, part of the backside of the lining structure was set as the loose contact area. Considering the cause of the imperfect contact status between the lining structure and surrounding rock, the numerical simulation of the loose contact status was divided into two cases: (1) many small voids inside the loose area; (2) insufficient strength of rock or grouting material inside the loose area.

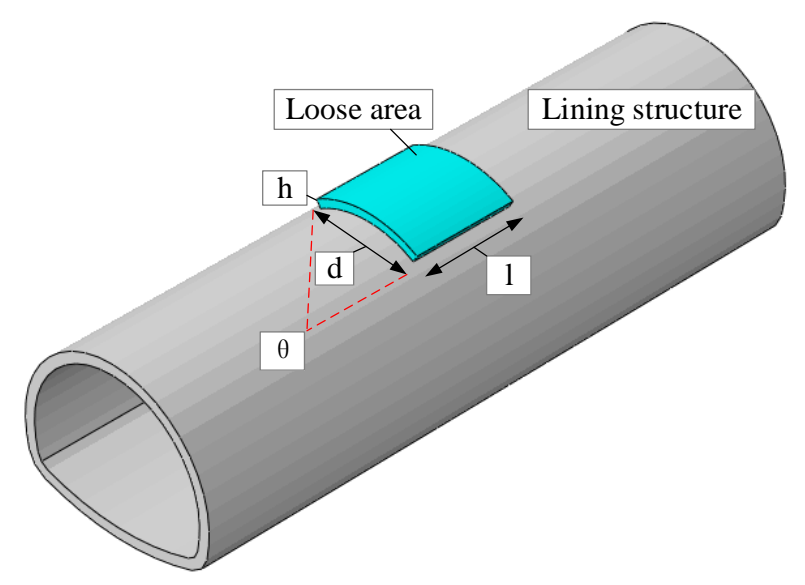

Figure 4. Tunnel geometry used in numerical simulations.

A numerical simulation model was built as shown in Figure 5. In this study, because the main purpose was to analyze the effects of loose contact between the lining and surrounding rocks, the lining was simplified as a whole. According to the design information, the thickness of the lining was taken as $0.65 \mathrm{~m}$. The depth of the tunnel was $18.72 \mathrm{~m}$. The parameters of surrounding rock used in the numerical simulation are shown in Table 2. To minimize the boundary effect [12], the distance between the boundaries and center of the tunnel should be 35 times the tunnel span. In this study, the model was $40 \mathrm{~m}$ long, $120 \mathrm{~m}$ wide, and $48 \mathrm{~m}$ high. The distance between the center of the tunnel and the lateral boundary was 5 times the tunnel span, whereas the distance between the bottom of the tunnel and the lower boundary was approximately 4 times the height of the tunnel. The mesh layout of the surrounding rock and the tunnel lining is shown in Figure 5. The mesh of the loose area and lining structure was refined to ensure the accuracy of the numerical calculation. There were 70,344 grids in total, and the grid type was the linear hexahedron element C3D8. 


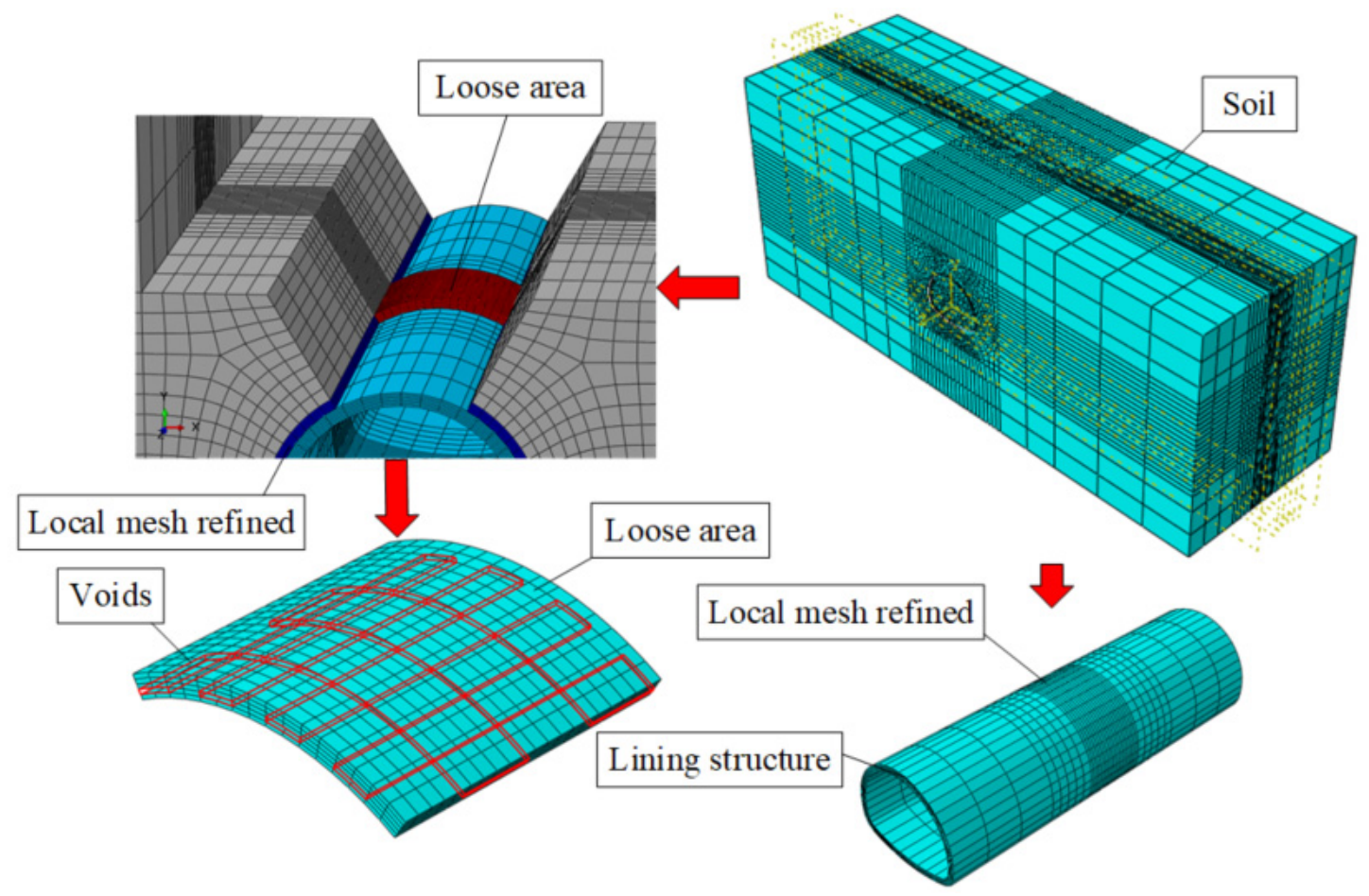

Figure 5. Numerical simulation model.

To study the variation of the contact pressure, the surface to surface contact mode was used in the interaction face between the lining and surrounding rock [39]. Penalty contact stiffness defined with an exponential law was applied normally, and coulomb friction (the friction coefficient was $0.8)$ was applied tangentially $[12,14]$. The surrounding rock was considered as ideal elastic-plastic material following the Mohr-Coulomb yield criterion [40]. Additionally, the horizontal displacement of the vertical boundary was restrained while the bottom of the model was restrained in the vertical direction [12]. According to the procedure of tunnel excavation, the geostatic procedure was selected to establish the initial geostatic stress field, and the lining and the void were activated at the same time after excavation.

\subsection{Model Test Verification}

To verify the correctness and effectiveness of the numerical simulation model, and determine the internal force and contact pressure of lining structure in the condition of a normal dense contact state between the lining and surrounding rocks, a model test was conducted. The model test apparatus had dimensions of $3.00 \mathrm{~m} \times 1.62 \mathrm{~m}$ (length $\times$ height) in the plane, and $0.3 \mathrm{~m}$ in thickness [12], as shown in Figure 6. According to the Chinese code of "Specifications for Design of Highway Tunnels" [34], the normal cross-section of the railway tunnel was designed, the reduced scale in the model tests was selected as 40 , and the similarity ratio of the elastic modulus was selected as 40 [12,39]. To satisfy the law of similarity, a mixture of barite powder, silica sand, and petroleum jelly in a weight ratio of 4:10:1, and a mixture of water and gypsum in a weight ratio of 0.9:1 were selected for the lining [12]. The detailed parameters used during the model test are shown in Table 3. 


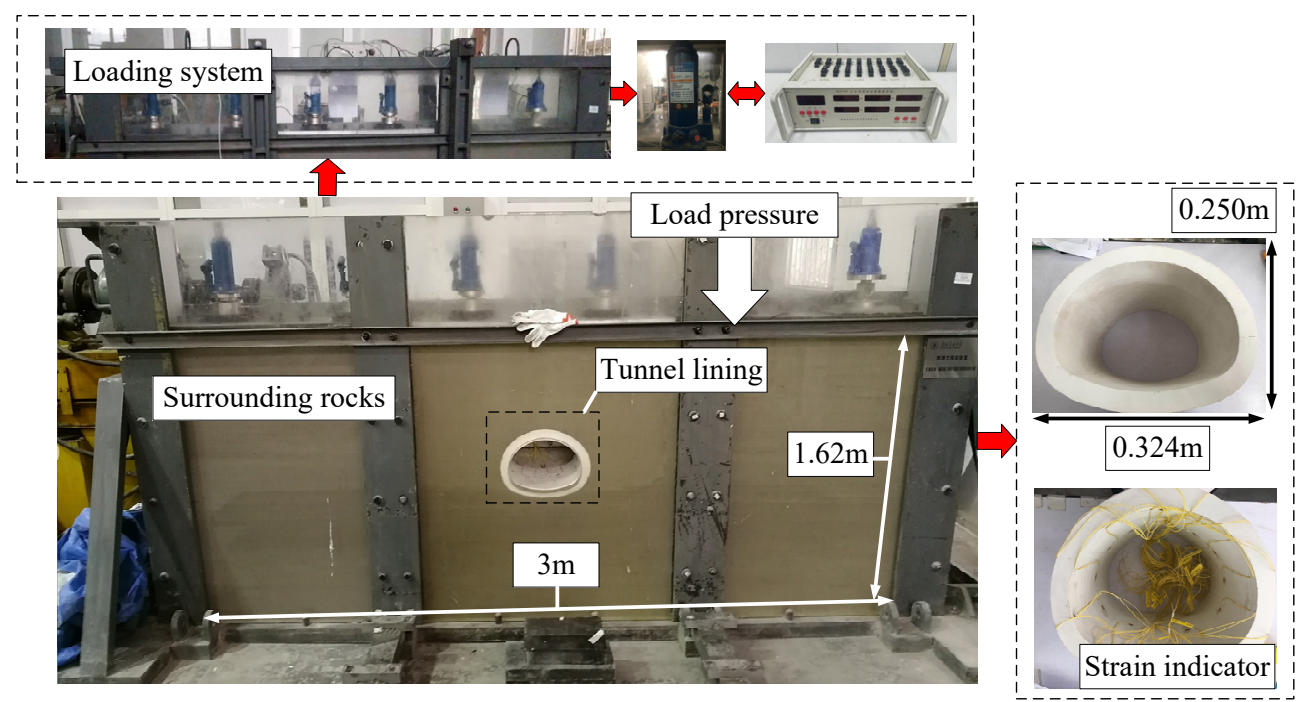

Figure 6. Model test apparatus.

Table 3. Mechanical parameters of model materials [12].

\begin{tabular}{cccccc}
\hline Cases & $\begin{array}{c}\text { Unit Weight } \\
\left(\mathbf{k N} / \mathbf{m}^{3}\right)\end{array}$ & $\begin{array}{c}\text { Elastic Modulus } \\
\mathbf{( G P a )}\end{array}$ & Poisson's Ratio & $\begin{array}{c}\text { Cohesive } \\
\text { Force }(\mathbf{k P a})\end{array}$ & $\begin{array}{c}\text { Friction } \\
\left.\text { Angle } \mathbf{(}^{\circ}\right)\end{array}$ \\
\hline Surrounding rock & 18 & 0.00675 & 0.37 & 4.6 & 24 \\
Lining structure & 25 & 0.874 & 0.2 & $/$ & $/$ \\
\hline
\end{tabular}

As the loading system gradually increased the pressure on the surrounding rocks, the variation of the lining stress was measured by the strain indicator, as shown in Figure 6. The comparison between the numerical simulation results and model test results is shown in Figure 7 . When the overload reached $0.04 \mathrm{MPa}$ in the numerical model (0.01 $\mathrm{MPa}$ in the model test), the changes in contact pressure on the lining and the bending moment of lining that were obtained by the numerical simulation and model test has similar variation rules. Thus, the accuracy of the numerical simulation model could be verified. Besides, the value of the internal force, contact pressure, and displacement of the lining in the condition of dense contact with surrounding rocks could be determined. Those values could be used for the comparison of the influence of the contact state changes between the lining and surrounding rocks in the following research.

\subsection{Simulation Cases}

According to the classification of the loose contact status behind the tunnel lining in Table 1, as for the condition of the small voids inside the loose area, the compactness of the loose area could be simulated as follows: (1) first of all, loose area rock was divided into several small parts, the percentage volume of each part in the total volume of the loose area could be calculated; (2) then, the divided parts were removed to simulate the voids, as shown in Figure 5; (3) finally, the compactness could be obtained from the percentage of volume of the remaining parts inside the loose area in the total volume of the loose area. Seven different compactness degrees $(10 \%, 20 \%, 30 \%, 40 \%, 50 \%, 60 \%, 70 \%$, $80 \%$ ) were adopted for this research. Meanwhile, as for the insufficient strength of the loose area rock, insufficient strength was simulated by gradually reducing the rock strength parameters. The strength of rock in the loose area was weakened by 30\%,50\%, 70\%, and $90 \%$, respectively. 

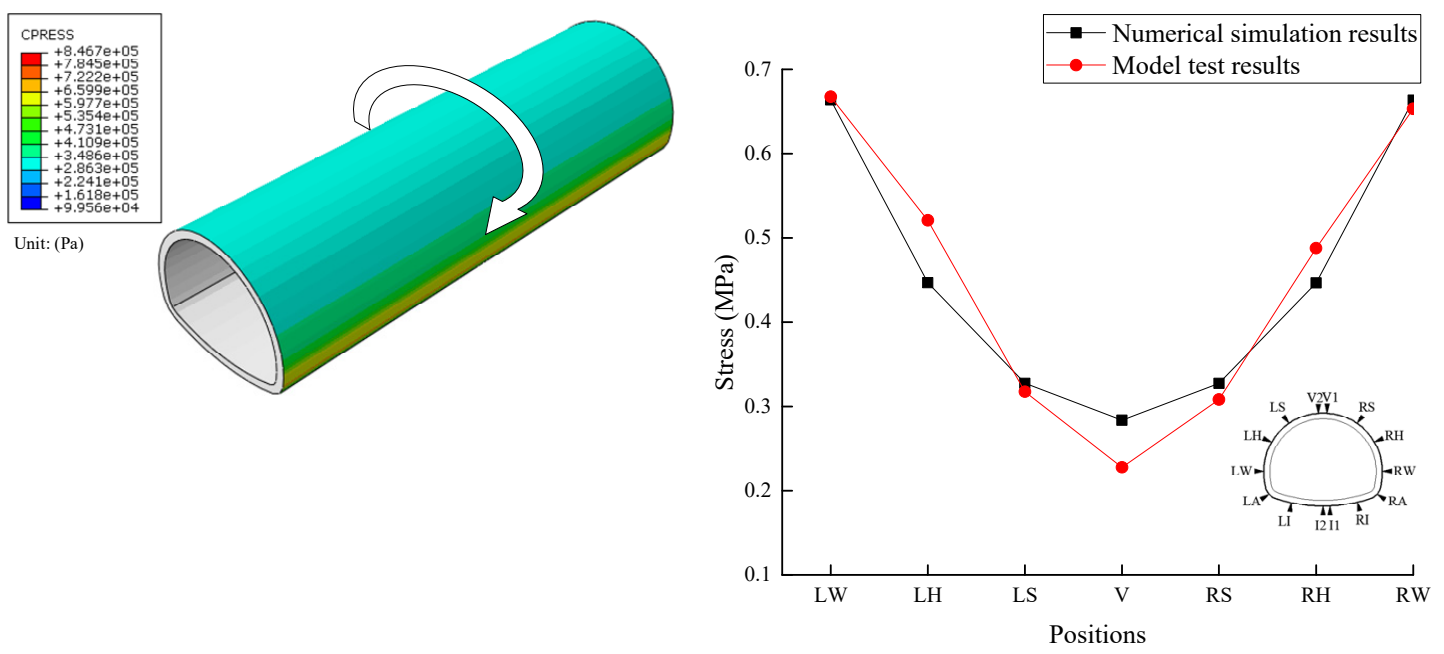

(a)

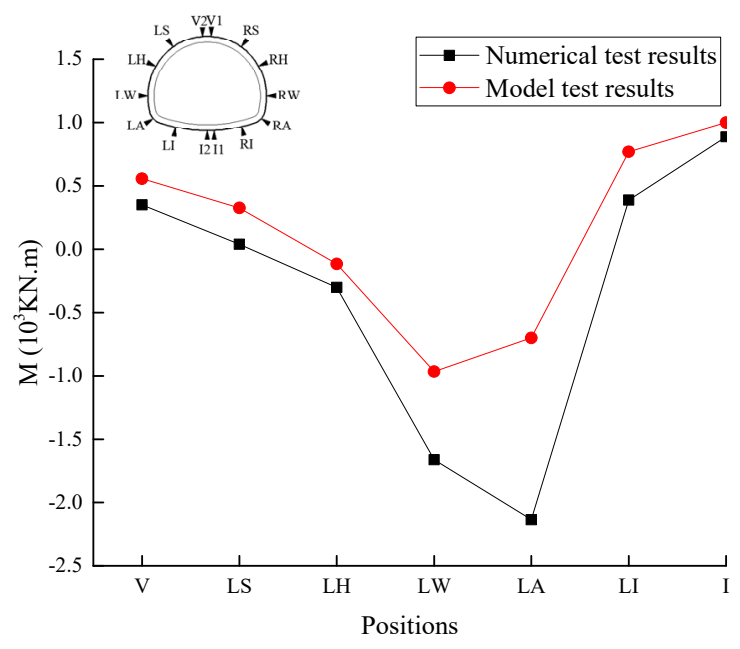

(b)

Figure 7. The comparison between numerical simulation results and model test results. (a) contact pressure, (b) bending moment.

Detailed simulation cases were designed, as shown in Table 4. The influence of imperfect contact between the tunnel lining and surrounding rock was studied in this paper. At first, the influence of the compactness of the loose area on the safety of the lining structure were explored, as shown in Table 1 of part I. Based on the $0.5 \mathrm{~m}$ height of the loose area, the influence of compactness changes in the loose area at the vault of the tunnel lining was studied, and the variation law of the increase of the loose contact area on the safety of the lining structure was analyzed with a rock compactness of $50 \%$. Meanwhile, the influence of the reduced rock strength parameters surrounding the tunnel lining on the safety of the lining structure was studied, as shown in Table 1 of part II. 
Table 4. Simulation cases.

\begin{tabular}{|c|c|c|c|c|c|c|c|c|}
\hline \multirow[b]{2}{*}{ Category } & \multirow[b]{2}{*}{ Cases } & \multirow{2}{*}{$\begin{array}{l}\text { Rock Strength } \\
\text { Parameter } \\
\text { Reduced/ } \\
\text { Compactness (\%) }\end{array}$} & \multicolumn{5}{|c|}{ Size of the Loose Area } & \multirow[b]{2}{*}{ Example } \\
\hline & & & $\begin{array}{l}\text { Length } \\
\text { (m) }\end{array}$ & $\begin{array}{c}\text { Width } \\
\text { (m) }\end{array}$ & $\begin{array}{l}\text { Area } \\
\left(\mathrm{m}^{2}\right)\end{array}$ & $\begin{array}{l}\text { Height } \\
\text { (m) }\end{array}$ & Position & \\
\hline \multirow{13}{*}{ I } & D10 & 10 & & & & \multirow{13}{*}{0.5} & \multirow{13}{*}{ Vault } & \\
\hline & D20 & 20 & & & & & & \\
\hline & D30 & 30 & & & & & & \\
\hline & D40 & 40 & & & & & & \\
\hline & D50 & 50 & 6.6 & 6.6 & 43.56 & & & \\
\hline & D60 & 60 & & & & & & \\
\hline & D70 & 70 & & & & & & \\
\hline & D80 & 80 & & & & & & \\
\hline & V15D & \multirow{5}{*}{50} & 3.3 & 3.3 & 10.89 & & & \\
\hline & V30D & & 6.6 & 6.6 & 43.56 & & & \\
\hline & V45D & & 8.8 & 8.8 & 77.44 & & & \\
\hline & V60D & & 3.3 & 3.3 & 10.89 & & & \\
\hline & V80D & & 6.6 & 6.6 & 43.56 & & & \\
\hline \multirow{4}{*}{ II } & AP30 & 30 & \multirow{4}{*}{\multicolumn{2}{|c|}{ / }} & & \multirow{4}{*}{0.5} & \multirow{4}{*}{$\begin{array}{c}\text { Surround } \\
\text { tunnel } \\
\text { lining }\end{array}$} & \\
\hline & AP50 & 50 & & & & & & \\
\hline & AP70 & 70 & & & 1 & & & \\
\hline & AP90 & 90 & & & & & & \\
\hline
\end{tabular}

\section{Influence of Insufficient Compactness behind Tunnel Lining}

\subsection{Effect of the Compactness}

\subsubsection{Changes in the Internal Force}

To explore the influence of the compactness of the loose area on the safety of lining structure, a numerical simulation scheme was adopted as shown in Table 4. The variation law of the internal force of lining structure was simulated as the compactness increased from $0 \%$ to $100 \%$ in the loose area. When the compactness was $0 \%$, the lining structure did not contact with behind rock. When the compactness was $100 \%$, the lining structure densely contacted with surrounding rock.

The circumferential internal force varied with the compactness of the loose area behind lining, as shown in Figure 8. To highlight the trend of changes, the ratio of the internal force ( $M$ or $N)$ to the internal force of the densely contact status $\left(M_{n o r}\right.$ or $\left.N_{n o r}\right)$ was calculated. The circumferential axial force of the lining structure was extracted, as shown in Figure 8a. At the vault of the tunnel, the axial force of the lining structure was decreased by about $60 \%$ at most. With the increase of the compactness of the loose area, the axial force of the lining structure tends to the internal force of the dense contact state behind lining, which was the most significant when the density was greater than $70 \%$. Meanwhile, the circumferential bending moment of the lining structure was extracted, as shown in Figure $8 \mathrm{~b}$. With the increase of compactness, the bending moment of the lining structure at the vault and the haunch were changed most obviously compared with the dense contact state. The variation relationship between the bending moment at the vault and the haunch and the compactness of the lining structure were extracted, respectively. With the compactness of the loose area was decreased, the contact state between the lining structure and surrounding rock gradually approached the non-contact state (V60) due to the increase of voids inside the loose area. With the increase of the compactness of the loose area behind the lining, the lining structure at the vault of the tunnel bent outward and decreased gradually, while the lining structure at the haunch of the tunnel bent inward and increased. After the compactness was less than $70 \%$, the bending moment at the vault of the lining structure increased by about 29 times relative to the dense contact state, and the bending moment at the haunch of the lining structure increased about 2 times. 


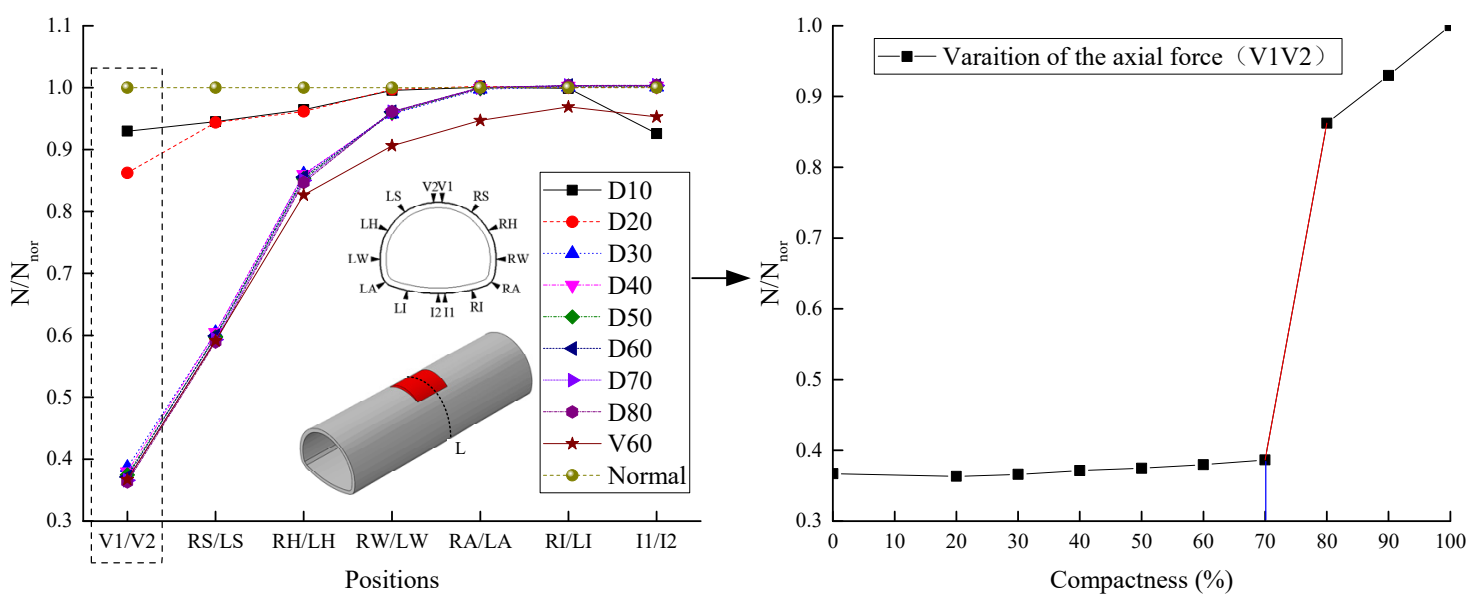

(a)

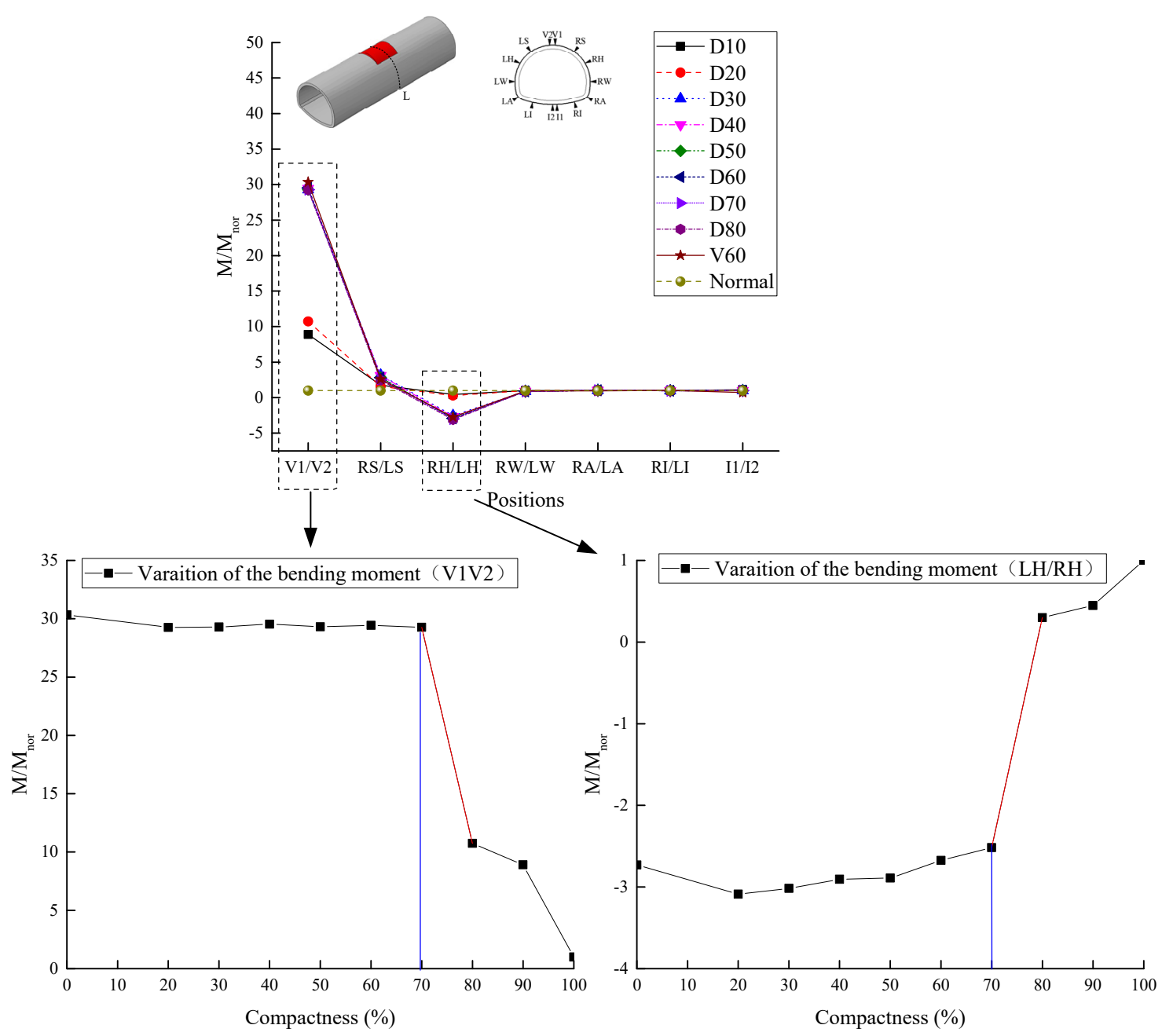

(b)

Figure 8. The variation of the circumferential internal force with the compactness of the loose area behind the lining. (a) axial force, (b) bending moment.

The variation of internal force along the longitudinal plane of the lining structure with the compactness of the loose area is shown in Figure 9. Changes of the axial force are shown in Figure 9a. The larger the compactness of the loose area, the smaller the changes of internal force of the lining 
structure. The lining structure at the vault was bent inward, while the structure within the loose area was uplifted into the interior of the loose area with the decrease of the compactness. Thus, the axial force of the lining structure at the vault inside the range of the loose area decreased significantly. However, the lining structure outside the loose area was not changed obviously, and the axial force of the lining structure was increased slightly only at a distance about $4 \mathrm{~m}$ from the edge of the loose area. Variation of the bending moment is shown in Figure $9 \mathrm{~b}$. The direction of the bending moment was not changed compared with the dense contact state behind the lining. The negative bending moment due to the lining structure being bent outward was increased with the decrease of the compactness within the loose area. The influence range of the loose area on the variation of the bending moment was almost $3 \mathrm{~m}$.

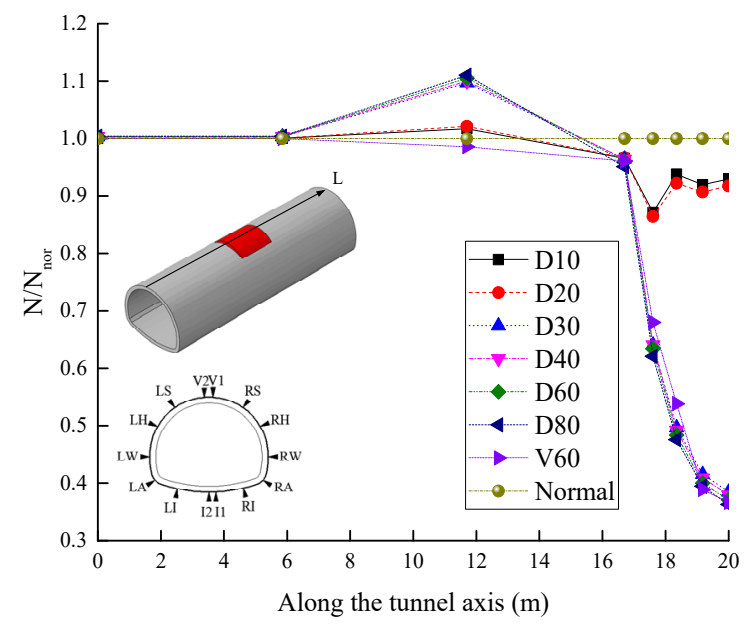

(a)

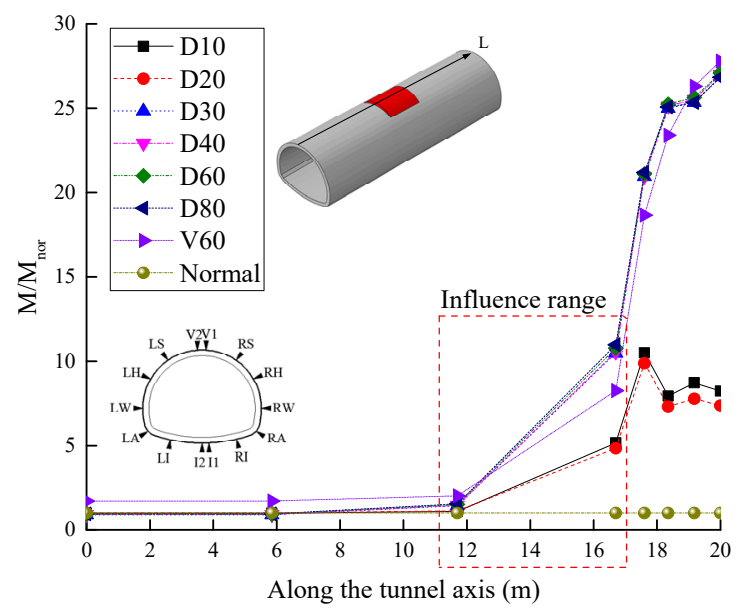

(b)

Figure 9. The variation of the internal force along the longitudinal of the lining structure with the compactness of the loose area. (a) axial force, (b) bending moment.

\subsubsection{Changes in the Contact Pressure}

Changes of the contact pressure between the lining structure and surrounding rock with the compactness of the loose area behind lining are shown in Figure 10. The distribution of the contact pressure along the tunnel axis is shown in Figure 10a. When the compactness of the loose area behind the lining was between $80 \%$ and $90 \%$, the distribution of contact pressure was very uneven due to some small voids that randomly existed behind the lining. When the compactness was decreased gradually, voids inside the loose area were connected gradually with each other, and finally a cavity was formed, which made the lining structure non-contacted with the surrounding rock. The contact pressure around the loose area behind the lining structure was increased regularly. The contact pressure reached its maximum after the lining structure completed non-contact with rock. The relationship between the maximum contact pressure and the compactness is shown in Figure 10b. The contact pressure of the lining structure in the 3-m range around the loose area was increased by nearly $50 \%$ compared with the dense contact state, while inside the loose area, it tended to be 0 as the compactness was decreased. Similarly, when the compactness was less than $70 \%$, the contact pressure was increased by nearly $30 \%$ compared with that of more than $70 \%$. 


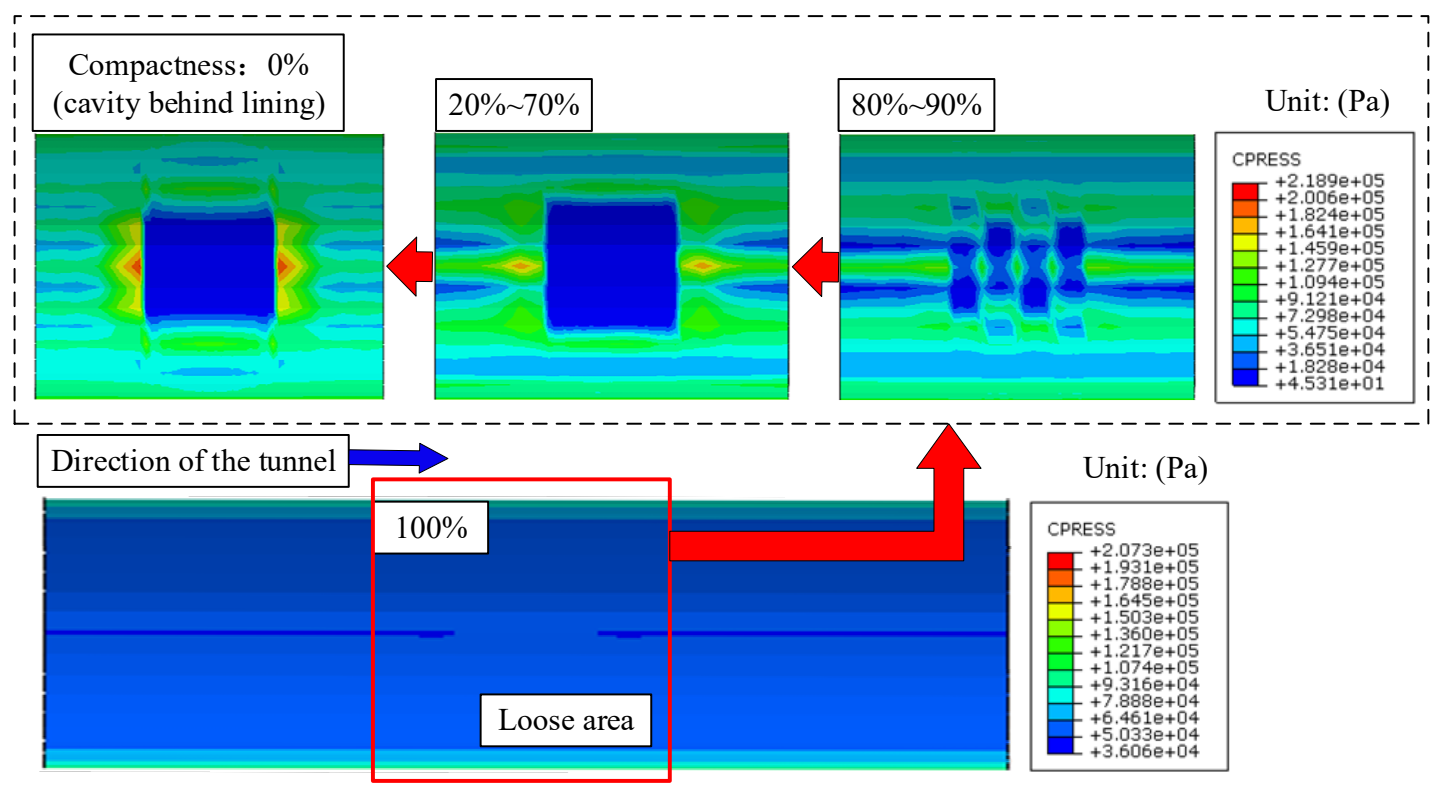

(a)

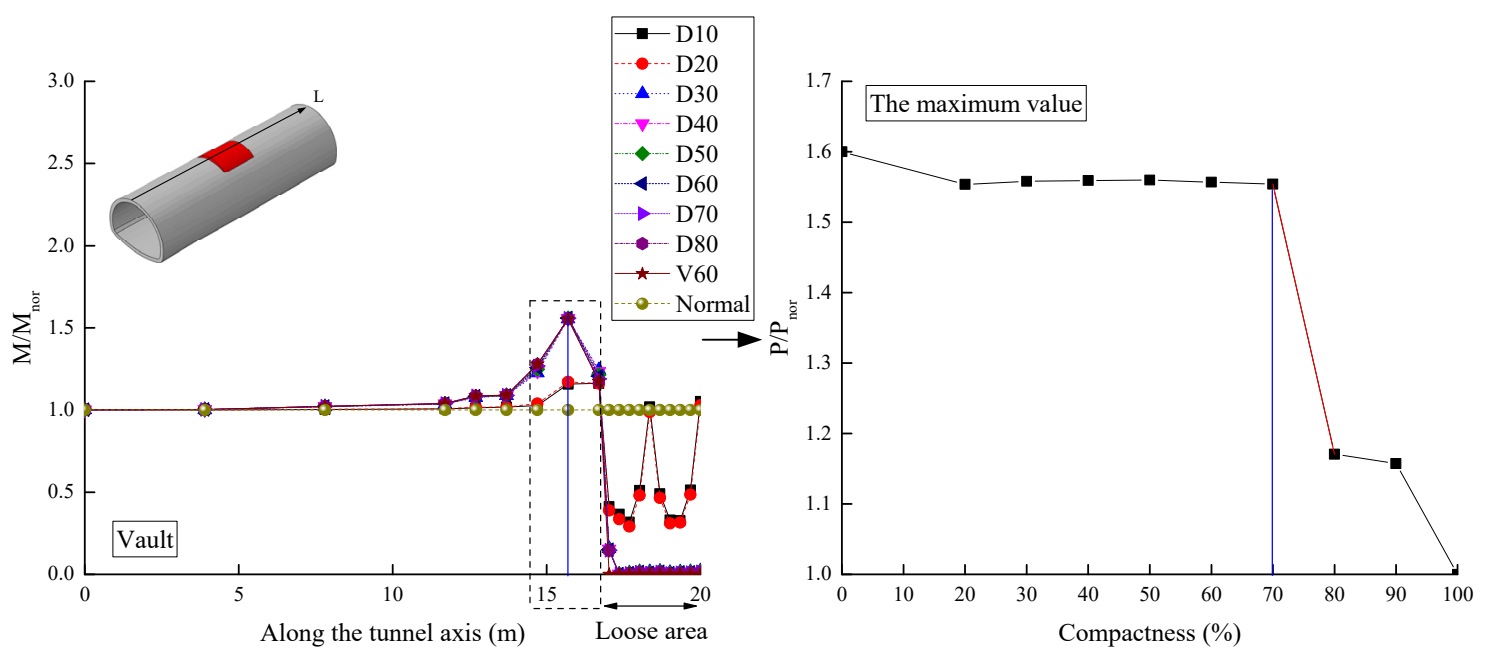

(b)

Figure 10. Changes of the contact pressure between the lining structure and surrounding rock with the compactness of the loose area behind the lining. (a) distribution of the contact pressure, (b) variation of the contact pressure along the tunnel axis.

\subsubsection{Changes in the Deformation}

Deformation of the lining structure variation with the compactness of the loose contact area is shown in Figure 11. The distribution of the lining structure displacement is shown in Figure 11a. Deformation of the lining structure was mainly concentrated on the center of the loose contact area behind the vault of the lining. With the decrease of the compactness, the deformation of the lining structure approached the condition of the void behind lining. The lining structure was bent outward at the vault, while the lining structure was bent inward at the haunch of the tunnel. The radial displacement of the lining structure at the vault and the haunch of the tunnel was increased gradually. The deformation of the lining structure along the tunnel axis was extracted and compared with the dense contact state, as shown in Figure 11b. The deformation of the lining structure happened mostly inside the loose contact area. The radial displacement of the vault of the tunnel changed abruptly when the compactness was 70\%, which increased by about 2 times compared with the dense contact state. 


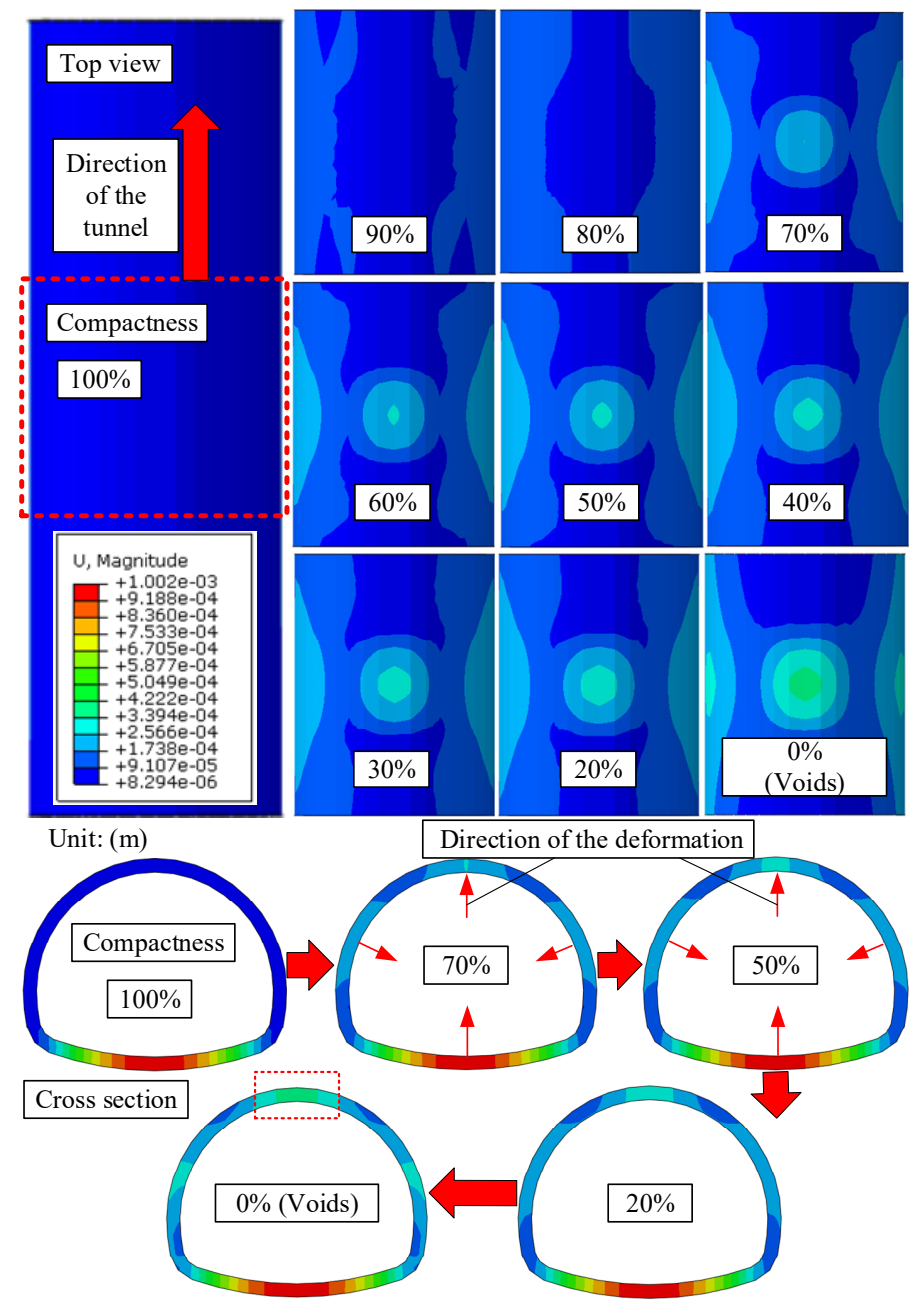

(a)

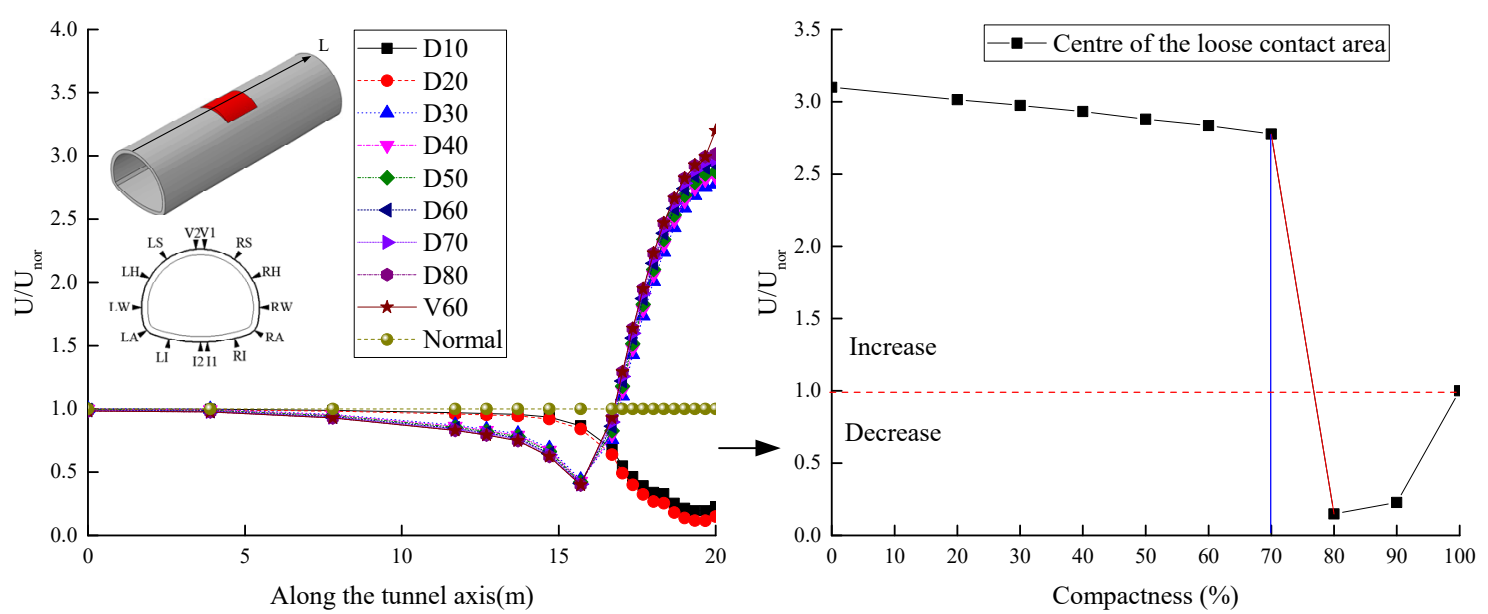

(b)

Figure 11. Deformation of the lining structure variation with the compactness of the loose contact area. (a) Distribution of the deformation, (b) The deformation of the lining structure along the tunnel axis. 
Above all, as for the back-fill grouting treatment for the cavity behind lining, the compactness of the grouting area should be above $70 \%$. In order to strictly prevent unwilling deformation of the lining structure and cracks from happening, it is recommended that the compactness of the grouting area should be above $80 \%$. Otherwise, the safety of the lining structure will be extremely harmed; if the voids inside the loose area connected with each other, a bigger cavity was formed, which made the internal force of the lining structure be distributed unevenly.

\subsection{Effect of the Loose Contact Area}

\subsubsection{Changes in the Internal Force}

To explore the influence of the change of the loose contact area on the safety of the lining structure, a loose area with the density of $50 \%$ was set behind the vault of the tunnel. The simulation cases of the loose contact area are shown in Table 4, which were respectively V15D, V30D, V45D, V60D, and V80D. The length and width of the loose contact area behind the lining increased proportionally. The variation of the internal force of the lining structure is shown in Figure 12. Changes of the axial force of the lining structure are shown in Figure 12a. With the increase of the loose contact area, the axial force of the lining structure at the vault was under tension and reduced gradually, which was about $80 \%$ less than the dense contact state. The variation of the bending moment of the lining structure is shown in Figure 12b. Compared with the dense contact state, with the increase of the loose contact area, the biggest changes in the bending moment of the lining structure inside the loose contact area were at the vault and the haunch of the tunnel, and the other positions showed smaller changes. The variations of the bending moment of the lining structure at the vault and the haunch with the loose contact area were extracted. Similar with the condition of the void behind the lining, the bending moment of the lining structure at the vault was bent outward and increased with the growth of the loose contact area significantly. When the loose contact area behind the lining structure at the haunch of the tunnel was greater than about $25 \mathrm{~m}^{2}$, the direction of the bending moment of the lining structure was changed, and the lining structure was changed from bending outward to bending inward.

\subsubsection{Changes in the Contact Pressure}

The variation of the contact pressure between the lining structure and surrounding rock is shown in Figure 13. The distribution of the contact pressure is shown in Figure 13a. With the increase of the loose contact area, the contact pressure within the loose contact area approached 0 ; similar with the condition of the void behind lining, the contact pressure around the loose contact area was increased significantly. The contact pressure was extracted along the longitudinal direction of the vault of the tunnel, and compared with the dense contact state, as shown in Figure 13b. The maximum contact pressure appeared around the loose contact area, and it increased with the growth of the loose contact area, which was about 2 times the normal dense contact state at most. 


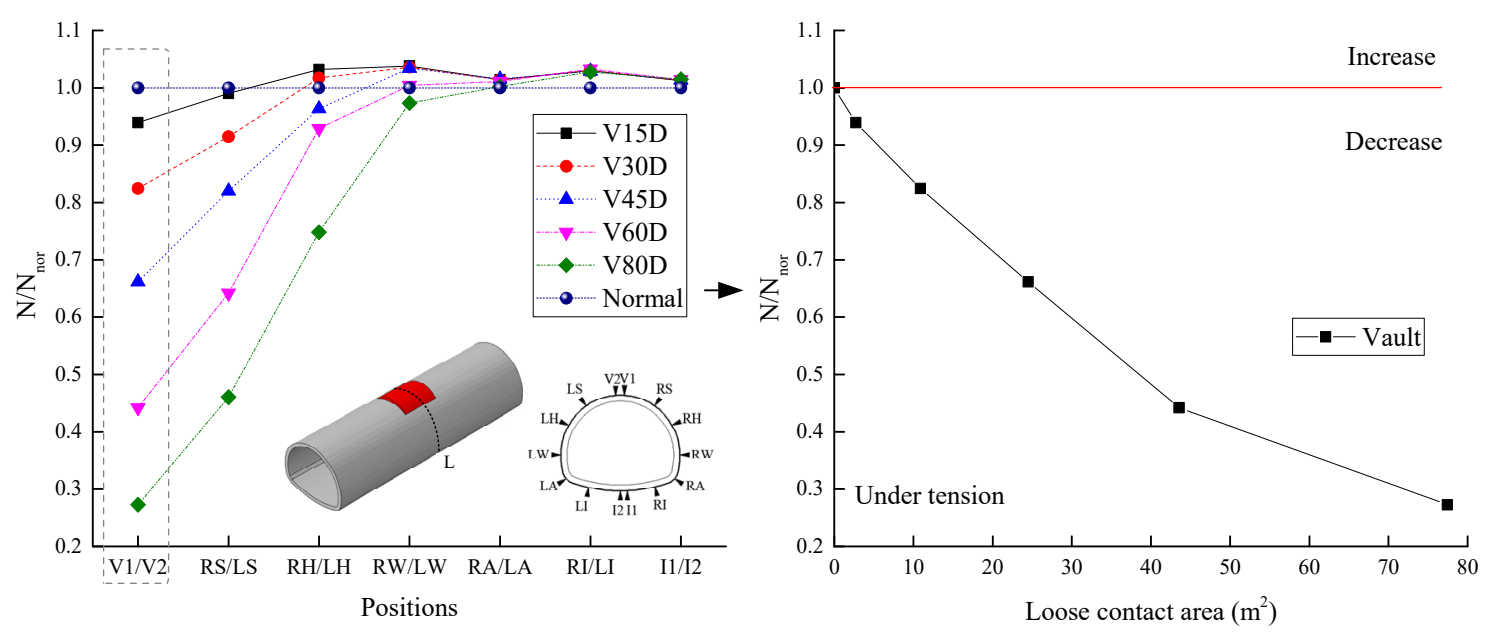

(a)

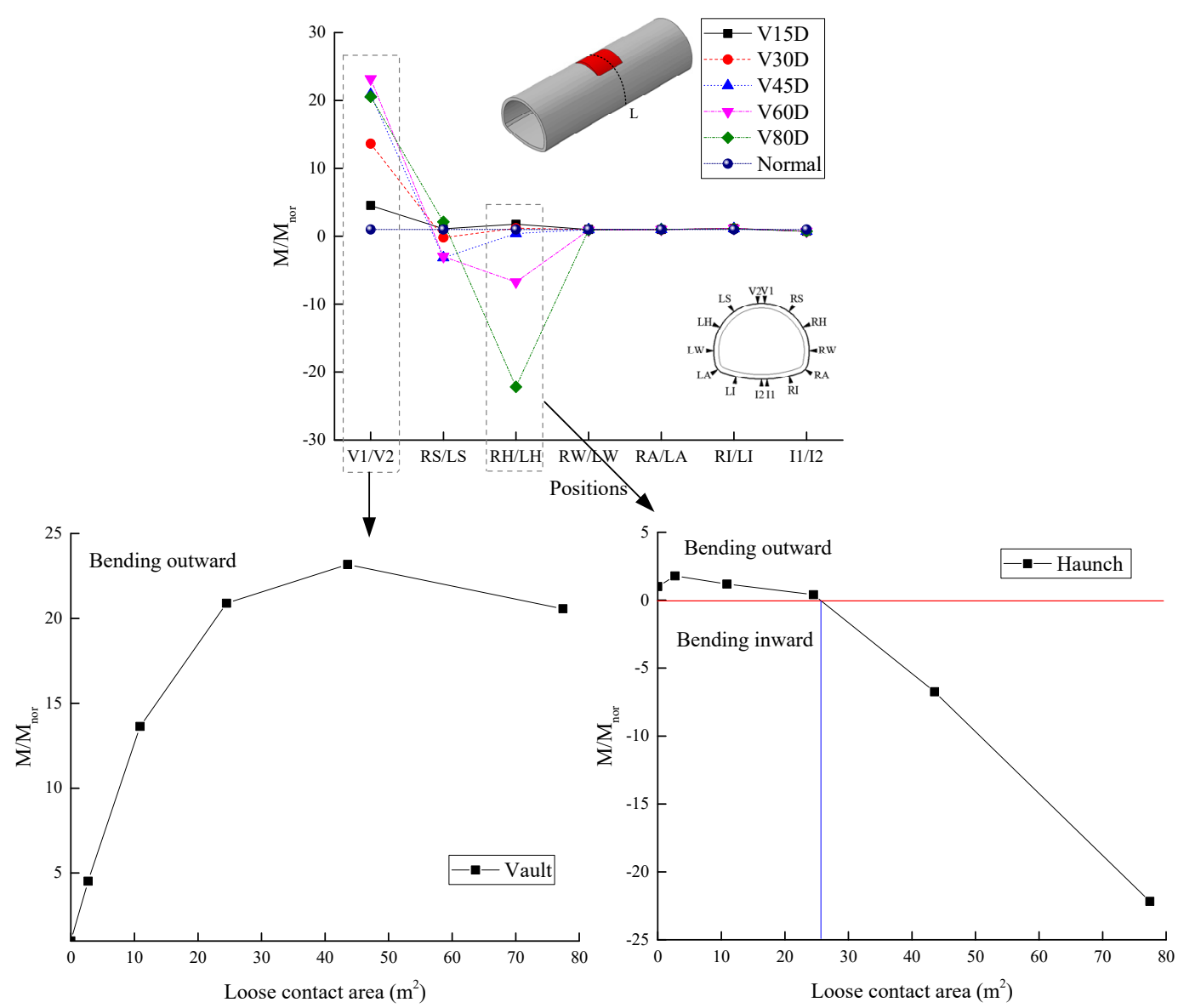

(b)

Figure 12. The internal force of the lining structure. (a) axial force, (b) bending moment. 


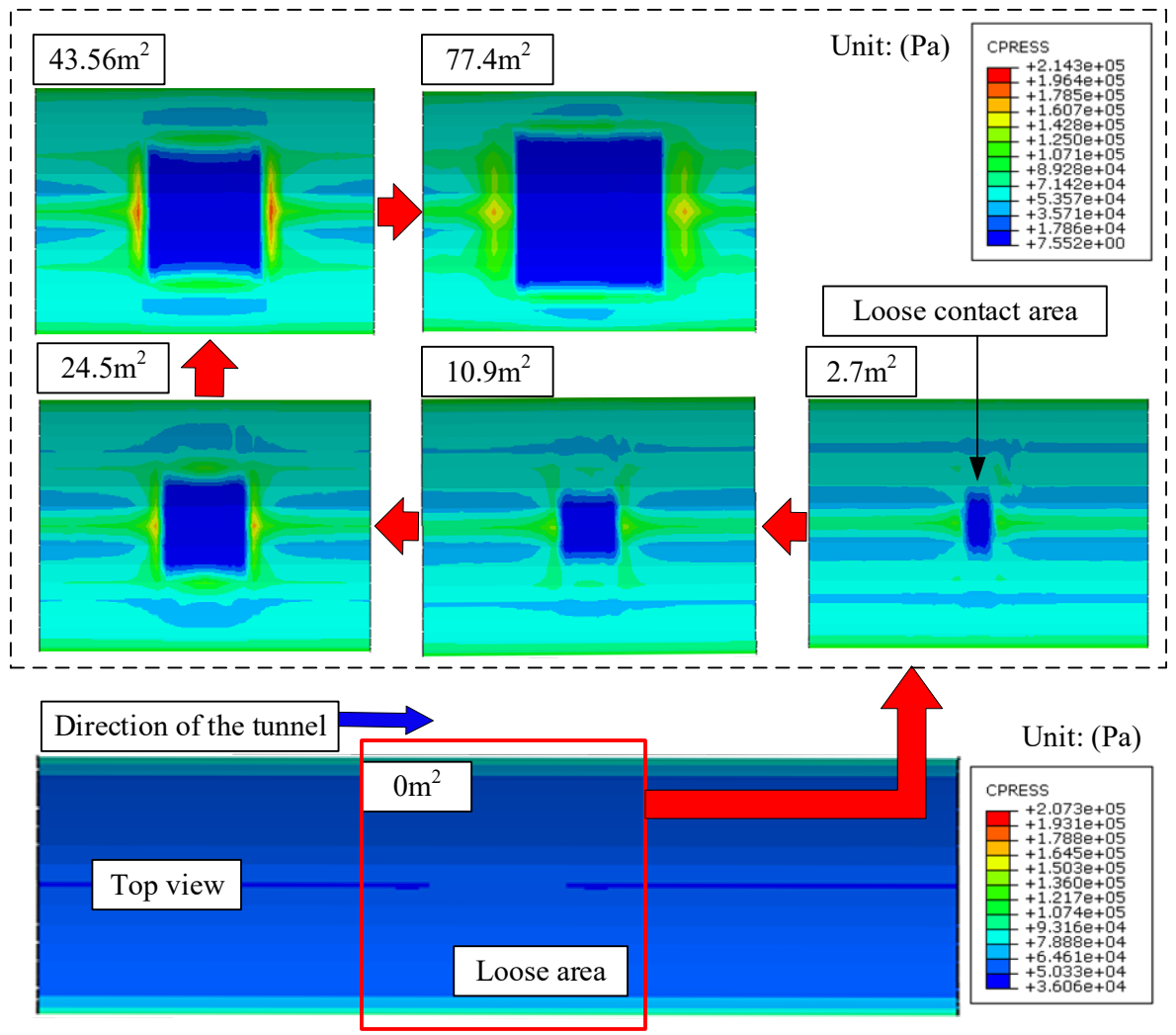

(a)
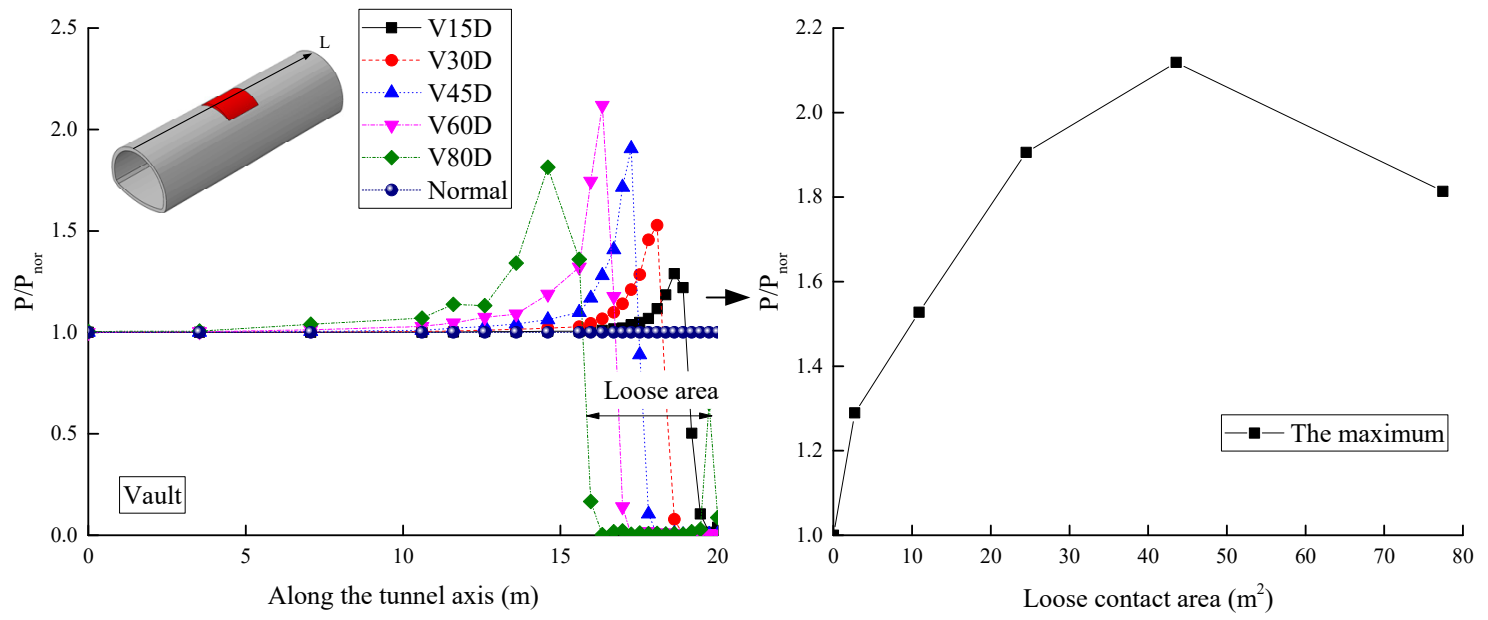

(b)

Figure 13. Variation of the contact pressure between the lining structure and surrounding rock. (a) distribution of the contact pressure, (b) variation of the contact pressure along the tunnel axis.

\subsubsection{Changes in the Deformation}

Influenced by the insufficient compactness of the loose area behind lining, the variation of the displacement at the vault of the lining structure is shown in Figure 14. The distribution of the deformation of the lining structure is shown in Figure 14a. The vertical displacement towards the outside of the lining structure at the vault of the tunnel gradually increased with the growth of the loose contact area. The vertical displacement at the vault of the tunnel in different cases were extracted, and the maximum value were compared, as shown in Figure 14b. The deformation of the lining structure was mainly concentrated in the structure within the loose area. The deformation of the lining 
structure outside the loose area did not change much compared with the dense contact state. The loose contact area was directly proportional to the deformation of the lining structure at the vault.

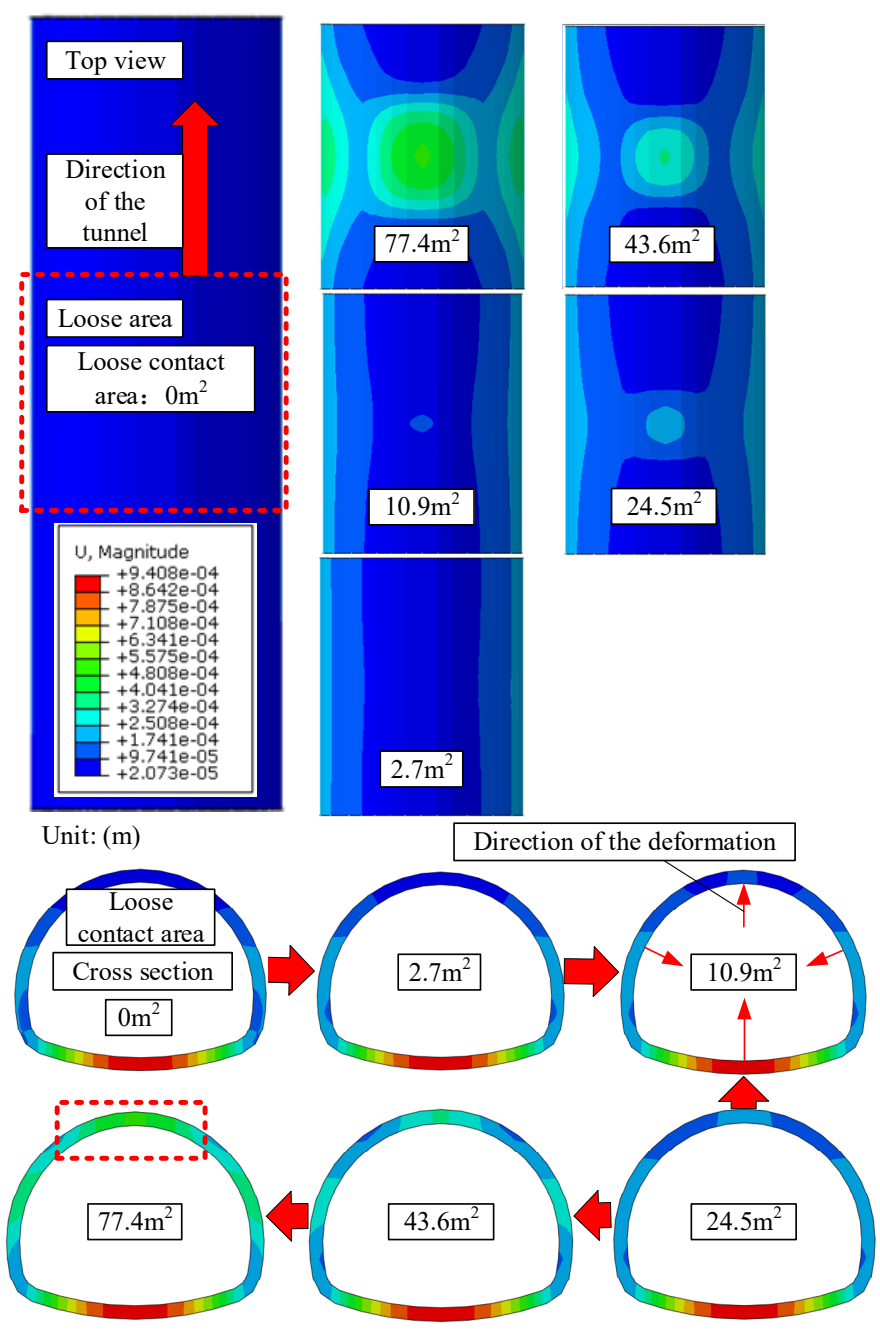

(a)

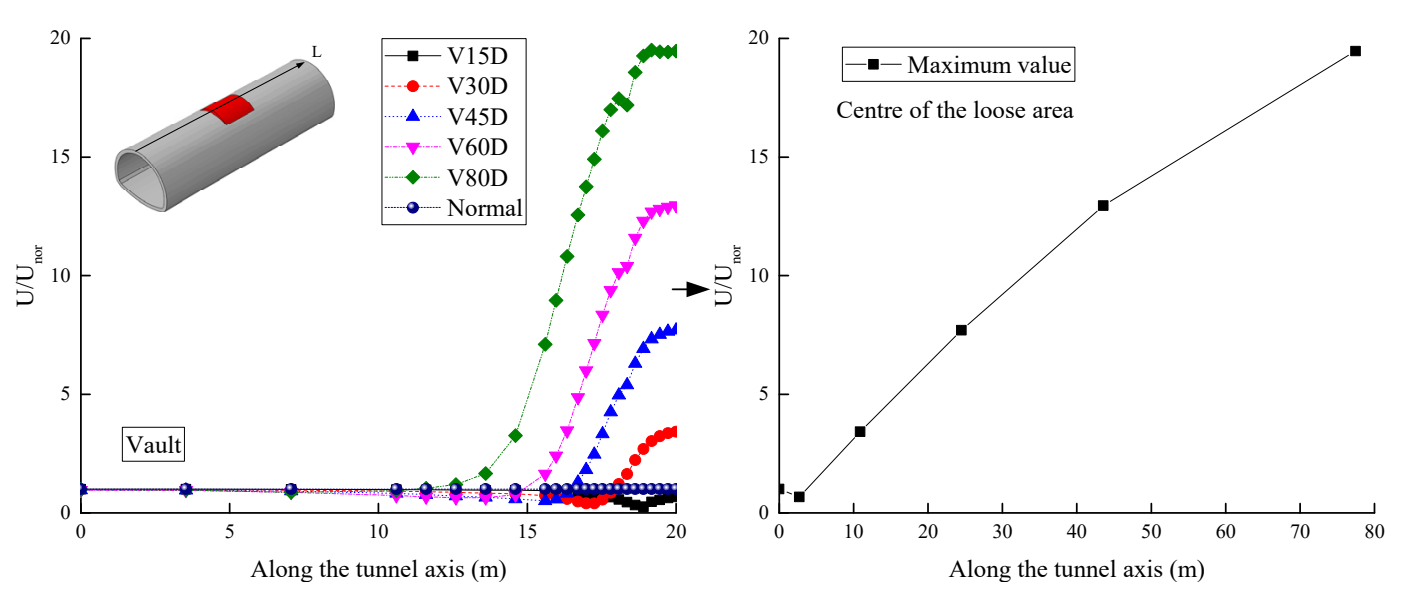

(b)

Figure 14. Deformation of the lining structure variation with the loose contact area. (a) distribution of the deformation, (b) deformation of the lining structure along the tunnel axis at the vault. 
In conclusion, when the range of the loose contact area was improved to 60 degree, the stress of the lining structure changed. The contact pressure and the vertical displacement of the lining structure at the vault increased by multiple times, and lining cracking may have easily occurred at this moment. Therefore, the loose contact area should be properly inspected and treated in time, in order to avoid enlargement of the loose area, and to maintain the stability of the lining structure.

\section{Influence of Insufficient Strength behind Tunnel Lining}

\subsection{Variation of the Internal Force}

To explore the influence of the strength parameters of the back-fill grouting in the loose area on the safety of the lining structure, rock parameters in the loose area were reduced by $30 \%, 50 \%, 70 \%$, and $90 \%$, respectively, as shown in the case of AP30, AP50, AP70, and AP90. The internal force of the lining structure in different cases were compared as shown in Figure 15. With the decrease of rock strength in the loose area, the bending moment at the haunch of the tunnel was changed most obviously. The lining structure was bent inward at this position and increased gradually with the rock strength. When the strength of rock was weakened by $50 \%$, the increasing range of the bending moment was gradually raised. However, the axial force of the lining structure did not change much compared with the normal dense contact state.

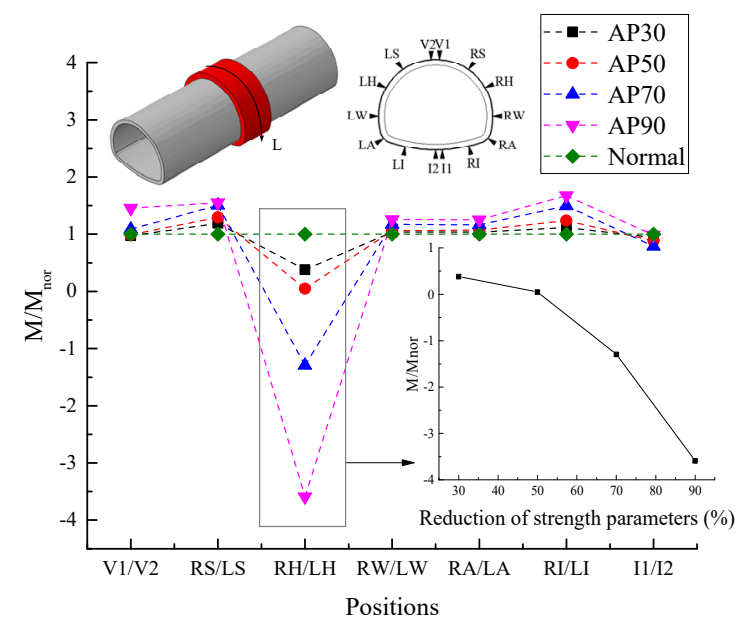

(a)

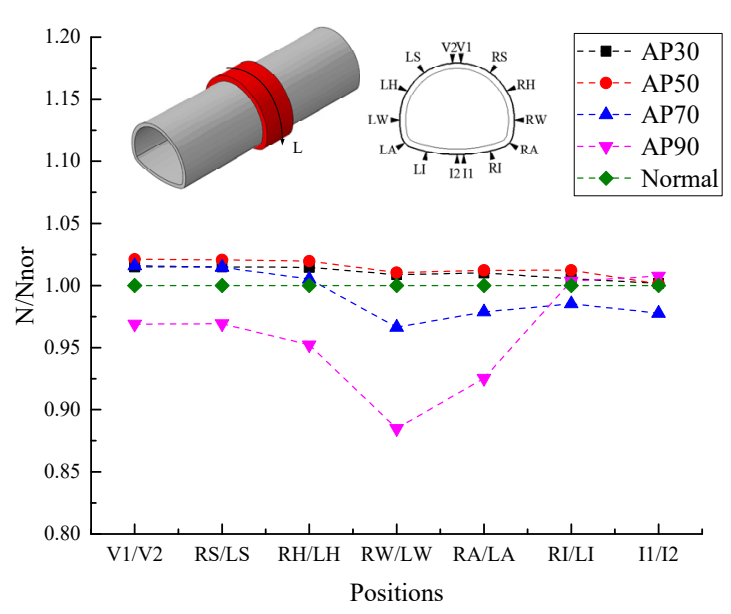

(b)

Figure 15. The internal force of the lining structure. (a) bending moment, (b) axial force.

\subsection{Variation of the Contact Pressure}

The variation of the contact pressure between the lining and the surrounding rock in the loose area with rock strength is shown in Figure 16. The distribution of the contact pressure is shown in Figure 16a. When the rock strength changed in the loose area, the variation of the contact pressure was mainly concentrated on the lining structure within the loose area. Due to the weakening of the surrounding rock strength around the lining structure, the distribution of contact pressure was different from that in the normal dense contact state, and the contact pressure at the vault was increased gradually. The variation of the contact pressure along the circumferential direction of the lining structure within the loose area is shown in Figure 16b. Due to the strength difference between rock in the loose area and rock in the outside area, the lining structure within the loose area at the vault of the tunnel was inward uplifted, and the maximum contact pressure was transferred from the arch springer in the normal dense contact state to both sides of the center of the arch bottom. The maximum contact pressure changed with the strength of rock in the loose area, as shown in Figure 16b. With the weakening 
strength of rock in the loose area, the maximum contact pressure was increased, which reached about 2 times the normal dense contact.

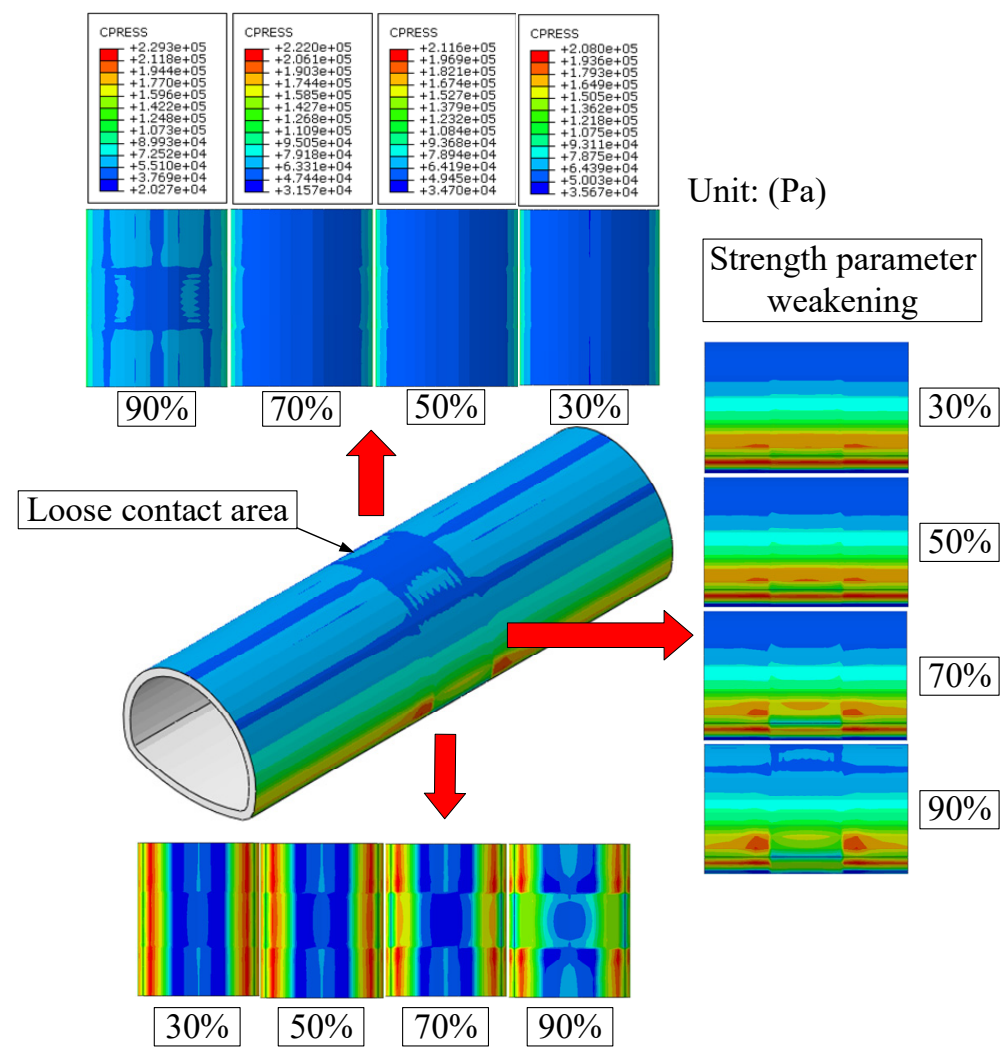

(a)

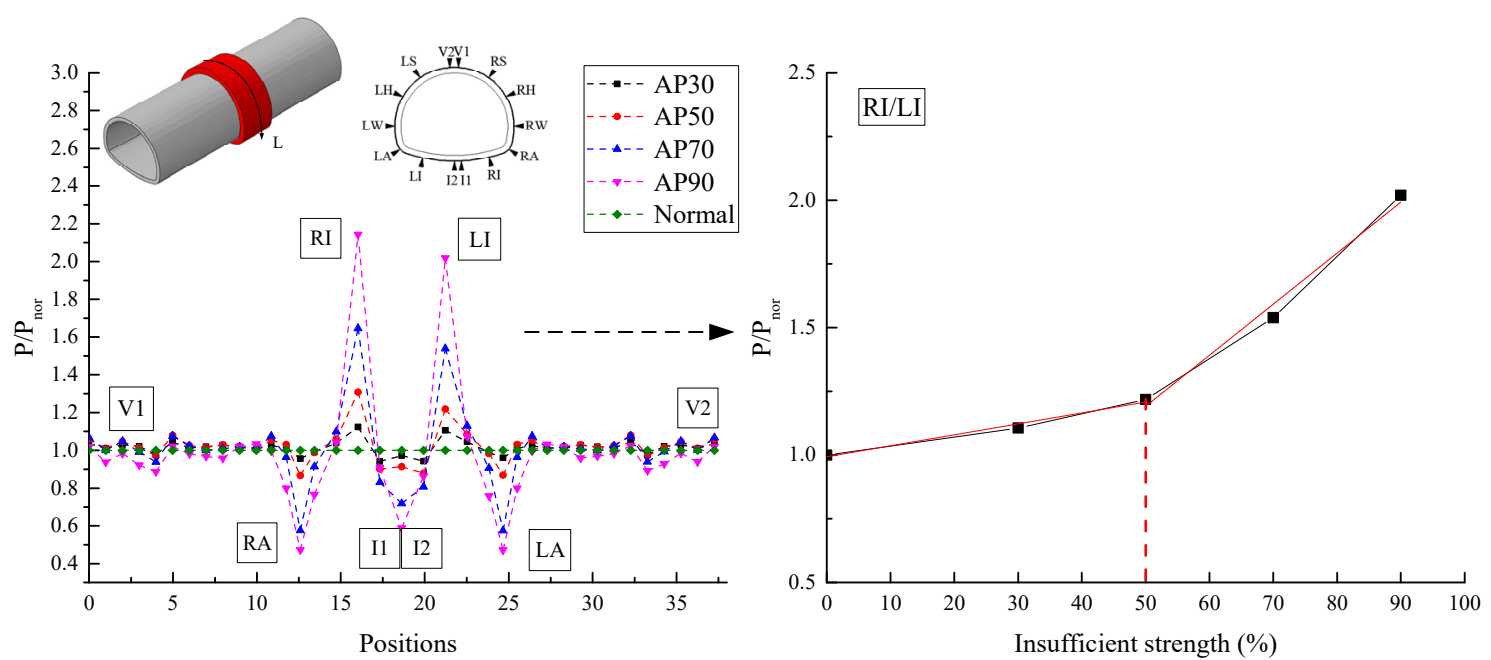

(b)

Figure 16. Variation of the contact pressure between the lining structure and surrounding rock. (a) distribution of the contact pressure, (b) variation of the contact pressure along the circumferential direction of the lining structure.

\subsection{Variation of the Deformation}

The deformation of the lining structure along the vault of the tunnel under the load (100 $\mathrm{kPa}$ ) was extracted as shown in Figure 17a. The deformation of the lining structure on both sides of the loose 
area was increased with the increase of the proportion of insufficient strength. The deformation of the lining structure in the loose area was relatively small since the strength of rock in the loose area became weaker than that in both sides. In the case of AP90, due to the rock strength being decreased seriously, the loose area was close to the non-contact state. The deformation range of the lining structure on both sides of the loose area became larger under the concentration of the stress, while the deformation of the lining structure within the loose area was small. The maximum displacement of the vault of the tunnel, which was the vertical displacement along the tunnel direction of $15 \mathrm{~m}$, was extracted for analysis as shown in Figure $17 \mathrm{~b}$. When the ratio of insufficient strength was exceeded by more than $30-50 \%$, the slope of the vertical displacement of the vault was increased significantly, and the corresponding displacement value was also increased obviously.

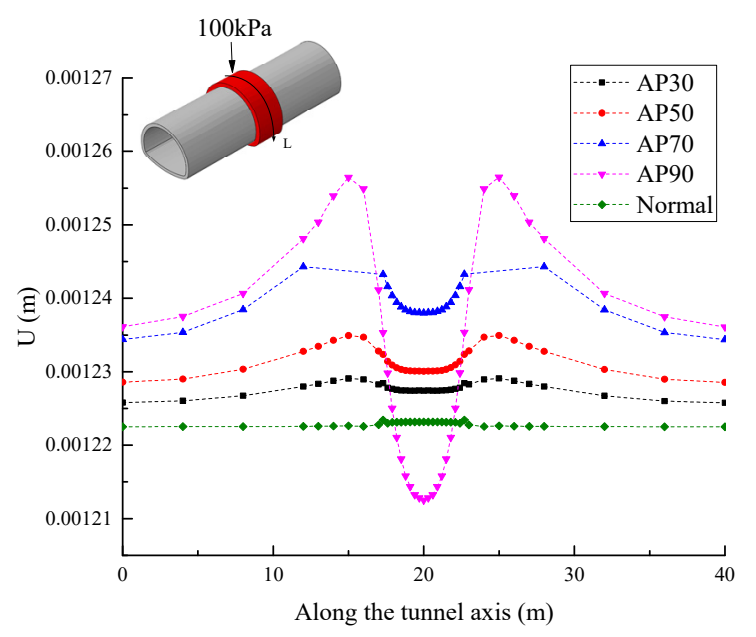

(a)

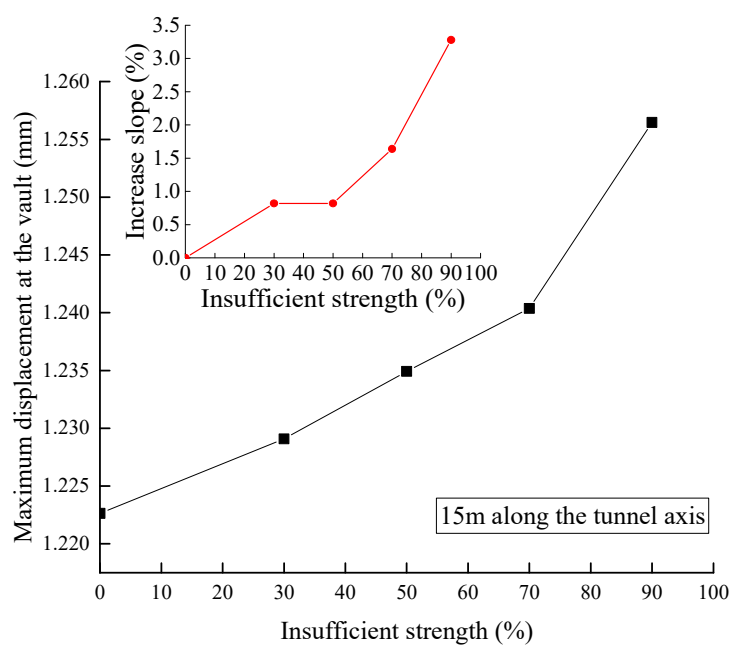

(b)

Figure 17. Deformation of the lining structure (a) displacement along the tunnel axis. (b) the maximum displacement varies with insufficient strength.

To sum up, due to the affection of the insufficient rock strength in the loose area, the influence of the lining structure safety was mainly concentrated in the structure of the loose contact area. The strength of the back-fill grouting behind lining should be above $50 \%$ of the strength of surrounding rock. Currently, in the use of the detection method for the uncompacted back-fill grouting behind lining, the location of the cavity can usually be easily found; however, specific information about the compactness was hard to accurately determine. To precisely distinguish the contact state between the lining structure and surrounding rock depends not only on the radar test image, but also needs to be verified by artificial drilling test.

\section{Grade Classification of the Lining Structure Safety Influenced by Loose Contact behind Lining}

\subsection{Comparison of the Influence of Internal Force and Safety Factor}

A comparison of the influence of the imperfect contact behind lining, which was caused by insufficient strength and compactness of the loose area rock behind the lining, with the internal force of the lining structure was made. At first, according to the numerical simulation analysis results, and based on the summary of the variation law of the internal force in different simulation cases, as shown in Figure 8, Figure 12, and Figure 15a, the variation of the internal force of the lining structure could be divided into four levels, which was A to D, standing for higher to lower influence. Meanwhile, the changes of the area of the insufficient strength behind the lining were considered and supplemented to ensure the integrality of the grade classification. Then, the percentage change of the internal force of 
the lining structure in the case of the imperfect contact was extracted and compared with the normal dense contact state, as shown in Figure 18.

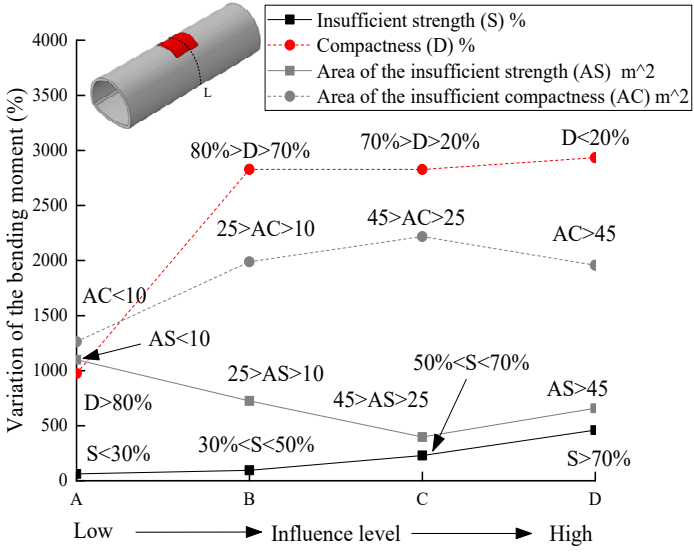

(a)

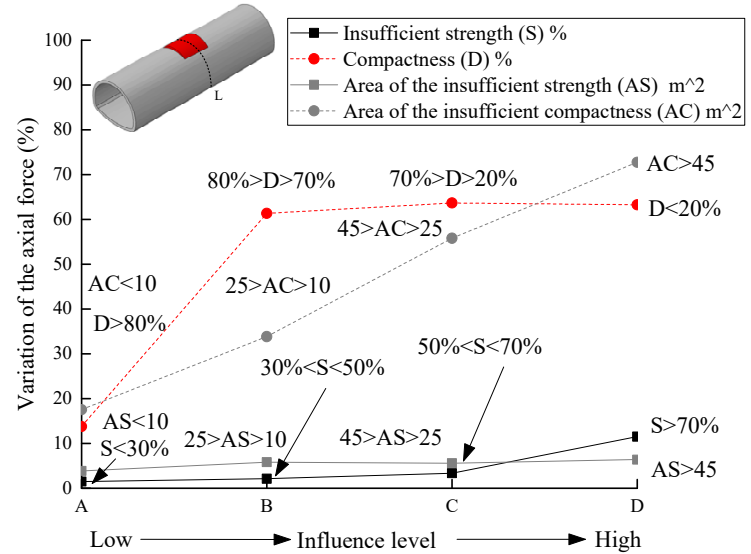

(b)

Figure 18. Comparison of the variation of the internal force. (a) bending moment, (b) axial force.

The comparison of the internal force of the lining structure is shown in Figure 18a,b. The insufficient compactness in the loose area had a greater effect on the internal force of the lining structure than the change of rock strength in the loose area. Compared with the normal dense contact state, in the condition of insufficient compactness behind the lining, the bending moment was changed between 10 and 30 times and the axial force was changed between $10 \%$ and $80 \%$. However, in the condition of insufficient strength of the rock parameters in the loose area, the bending moment was changed 10 times and the axial force was changed by less than $10 \%$. With the increase of the level of the imperfect contact, the influence of the compactness was greater than the influence of the area of loose contact on the internal force of the lining structure, while the influence of the insufficient strength parameters was slightly smaller than the influence of the area of loose contact.

The safety factor $(\mathrm{K})$ of the lining structure was calculated according to the Chinese code for designing railway tunnels $[34,41]$. The ultimate load-bearing capacity of the liner subjected to the eccentric compression was calculated in light of the ultimate strength of concrete. Determination of the safety factor $(\mathrm{K})$ was regarded as the most intuitive index to evaluate the safety of the liner [10].

Here, $e_{0}=\mathrm{M} / \mathrm{N} \leq 0.20 \mathrm{~h}$, where $e_{0}$ is the eccentricity of thrust force, $h$ is the thick of liner, $\mathrm{M}$ is bending moment, and $\mathrm{N}$ is the axial force. The axial force of the lining structure is determined by the compressive strength of concrete. Thus, $K_{c}$ was calculated using Equation (1):

$$
K_{c} N=\varphi \alpha R_{a} b h,
$$

where $\varphi$ is the longitudinal bending coefficient of the liner; $R_{a}$ is the compressive strength of concrete, which is $22.5 \mathrm{Mpa}$; $b$ is the width of the liner; and $\alpha$ is the eccentric effect factor of thrust force:

$$
\alpha=1+0.648\left(e_{0} / h\right)-12.569\left(e_{0} / h\right)^{2}+15.444\left(e_{0} / h\right)^{3},
$$

When $e_{0}=\mathrm{M} / \mathrm{N}>0.20 \mathrm{~h}$, where $e_{0}$ is the eccentricity of thrust force, $h$ is the thick of liner, $\mathrm{M}$ is the bending moment, and $\mathrm{N}$ is the thrust force. The axial force of the lining structure is determined by the tensile strength of concrete. Thus, $K_{t}$ was calculated using Equation (3):

$$
K_{t}=\frac{1.75 R_{t} b h \varphi}{N\left(\frac{6 e_{0}}{h}-1\right)}
$$

where $R_{t}$ is the tensile strength of concrete, which is $2.2 \mathrm{Mpa}$. 
The safety factor was calculated by Equations (1)-(3), as shown in Figure 19. The calculation results highly depend on the thickness of the lining and mechanical parameters of the surrounding rock. From the figure, the deficiency of the compactness in the loose contact area behind the lining had a greater influence on the decrease of the safety of the lining structure than the insufficient strength. In the condition of a lack of rock strength parameters, the lining structure safety was slightly decreased with the increase of the loose contact area caused by the insufficient rock strength. However, the safety of the lining structure can be significantly reduced, only after the loose area behind the lining was enlarged and connected with each other, and finally surrounded the tunnel. When the loose contact area was smaller than $25 \mathrm{~m}^{2}$, and the compactness bigger than $70 \%$ (From level A to C), the compactness of the loose area had a greater impact on the decrease of the safety factor of the lining compared with the area of loose contact. However, the influence of the loose contact area on the safety of the lining structure gradually dominated when the loose contact area exceeded the level C.

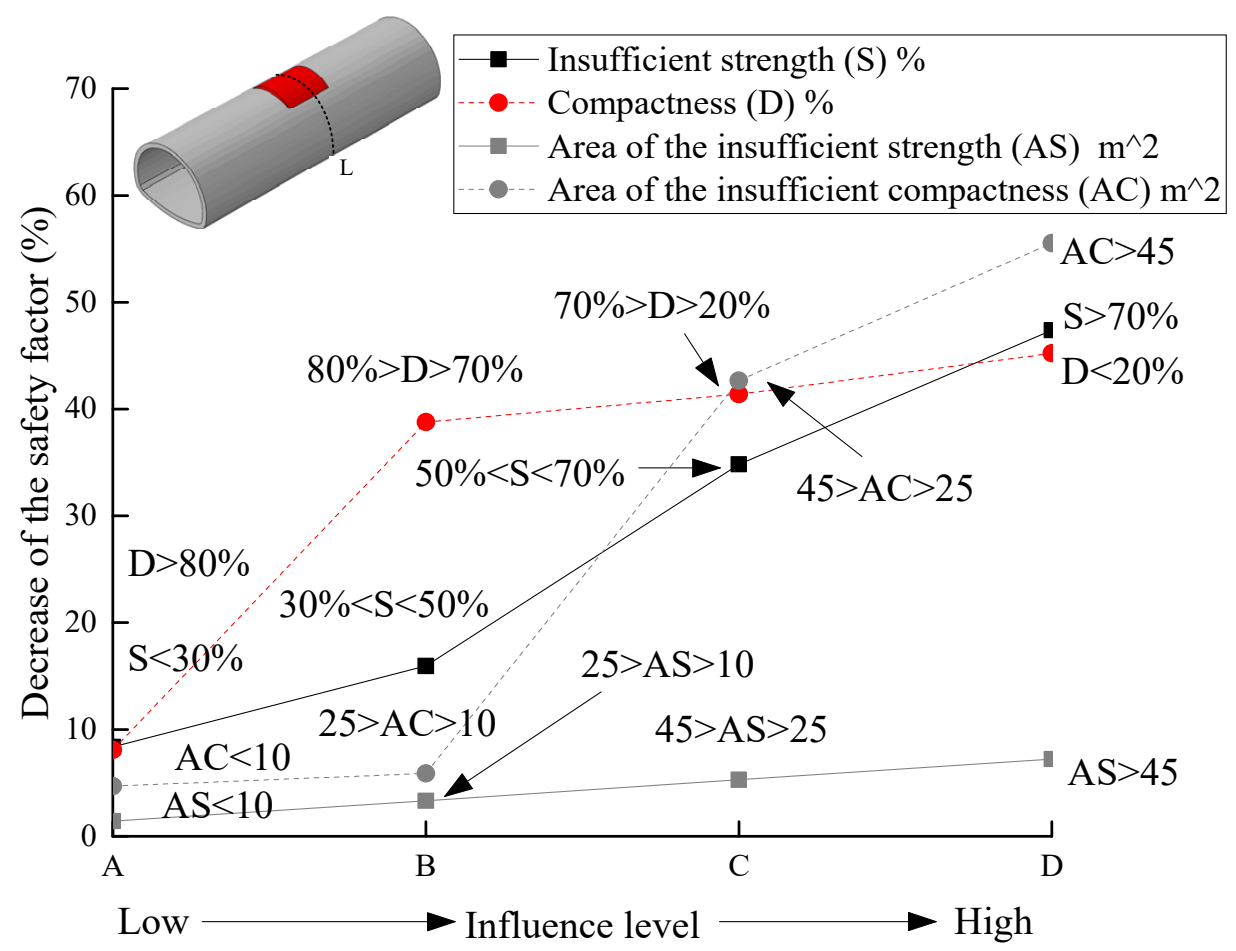

Figure 19. Comparison of the safety factor of the lining structure.

\subsection{Grade Classification}

To facilitate the application of the research results in practical projects, based on the decrease of the safety factor of the lining, the grade of the influence of loose contact on the safety of the lining structure was classified. The decrease percentage of the safety factor of the lining structure was ranked from small to big, as shown in Figure 20. For the convenience of the improvement construction and lining disease identification, the grade was classified based on the reduction ranges of the safety factor compared with the normal dense contact state, which were $0 \sim 5 \%, 5 \sim 20 \%, 20 \sim 40 \%$, and $40 \sim 60 \%$. Therefore, the safety impact was divided into four grades, from low to high, which were I, II, III, and IV, as shown in Table 5. 


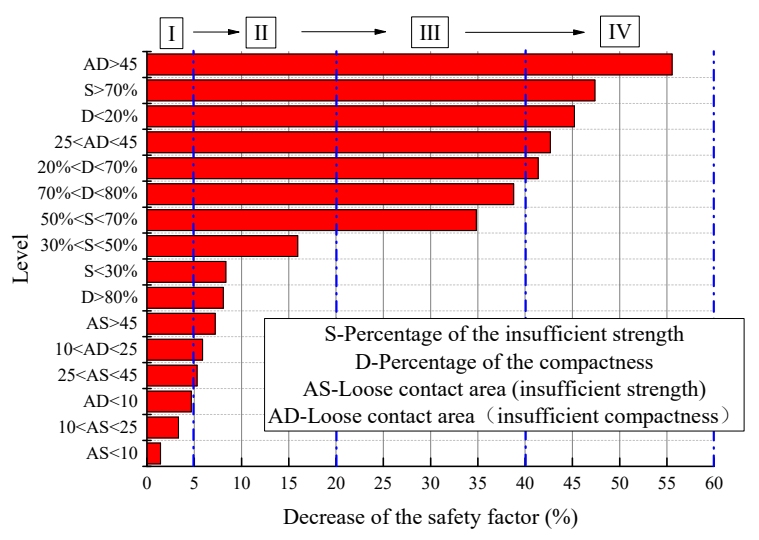

Figure 20. Rank of the reduction of the safety factor.

Table 5. Grade classification.

\begin{tabular}{|c|c|c|c|}
\hline Grade & $\begin{array}{l}\text { Description of the Influence on the Safety } \\
\text { of the Lining }\end{array}$ & $\begin{array}{l}\text { Decrease of the } \\
\text { Safety Factor }\end{array}$ & Identification Criteria \\
\hline I & Little influence & $0 \sim 5 \%$ & $\mathrm{AD}<10 ; \mathrm{AS}<25$ \\
\hline II & $\begin{array}{l}\text { Certain influence, the inspection frequency } \\
\text { should be improved, and daily } \\
\text { maintenance should be pay attention. }\end{array}$ & $5 \sim 20 \%$ & $\begin{array}{c}\mathrm{S}<50 \% ; 100 \%>\mathrm{D}>80 \% ; \mathrm{AS} \\
>25 ; 10<\mathrm{AD}<25\end{array}$ \\
\hline III & Big influence, suggest being repaired. & $20 \sim 40 \%$ & $50 \%<\mathrm{S}<70 \% ; 70 \%<\mathrm{D}<80 \%$ \\
\hline IV & $\begin{array}{l}\text { Significant influence, should be } \\
\text { treated immediately. }\end{array}$ & $40 \sim 60 \%$ & $\mathrm{D}<70 \% ; \mathrm{AD}>25 ; \mathrm{S}>70 \%$ \\
\hline
\end{tabular}

Note: The notation used in the identification criteria in the table was shown in the Figure 20. (i) "S" stands for the percentage of the insufficient strength, which can be explained as the reduction proportion of rock strength parameters inside the loose area behind lining. For example, $\mathrm{S}<50 \%$, which means rock strength of the loose area was reduced $50 \%$ compared with surrounding rock. (ii) To convenient the construction treatment, the unit of the loose contact area was $\mathrm{m}^{2}$, the corresponding range of the loose contact area was shown in Table 4. For example, 10 corresponding to the range of 30 degrees, 25 corresponding to the range of 45 degrees. (iii) It can be included into the corresponding influence grade if any one of the identification criteria was meet.

\section{Conclusions}

The effects of loose contact behind tunnel lining on the mechanical behavior of the lining structure were explored in this paper. According to the results of the field investigation, the influence of the compactness and insufficient strength of the loose contact area behind lining were discussed through numerical simulation analysis. The influence grade was classified based on the decrease of the safety factor of the lining structure. Conclusions were drawn as follows:

1. The influence factor of loose contact states behind lining can be divided into two categories based on the cause analysis in the field investigation: one was the compactness, another one was the insufficient strength parameters. The compactness in the loose contact area behind lining should be above $70 \%$. To strictly prevent unwilling deformation of the lining structure and cracks, it was recommended that the compactness should be above $80 \%$ after back-fill grouting. Meanwhile, the range of the loose contact area should be no more than 60 degree, otherwise the contact pressure and the vertical displacement of the lining structure at the vault were increased by multiple times.

2. The influence of the insufficient strength in the loose contact area behind lining on the lining structure safety was mainly concentrated within the loose contact region of the structure. The strength of the back-fill grouting behind lining should be above $50 \%$ strength of the surrounding rock, otherwise the safety of the lining structure will be extremely harmed, especially when the range of the loose area was increased, and the tunnel lining was gradually surrounded. Therefore, the strength of the back-fill grouting behind lining should be ensured. The loose contact area was developed and connected with each other, which should be avoided.

3. The influence of the compactness of the loose contact area on the safety of tunnel lining was greater than the influence of the strength. The impact on the safety increased with the area of 
the loose contact behind lining. The classification of the influence grade of loose contact on the safety of the lining structure not only provided scientific instruction to control the quality of the back-fill grouting properly, but also offered a valuable reference for the evaluation of the contact state between lining and surrounding rock.

Author Contributions: Writing - original draft preparation, software, data curation, visualization, formal analysis, Z.Y.; Conceptualization, writing-review and editing, supervision, funding acquisition, C.Z. All authors have read and agreed to the published version of the manuscript.

Funding: This research was funded by the National Natural Science Foundation of China, grant number 51978042.

Conflicts of Interest: We declare that there are no known conflicts of interest associated with this publication.

\section{References}

1. Ministry of Transport. Statistical Bulletin on the Development of the Transport Industry in 2019. Tunn. Constr. 2020, 40, 820 .

2. Wang, J.; Huang, H.; Xie, X.; Bobet, A. Void-induced liner deformation and stress redistribution. Tunn. Undergr. Space Technol. 2014, 40, 263-276. [CrossRef]

3. Yan, Q.; Xu, Y.; Zhang, W.; Geng, P.; Yang, W. Numerical analysis of the cracking and failure behaviors of segmental lining structure of an underwater shield tunnel subjected to a derailed high-speed train impact. Tunn. Undergr. Space Technol. 2018, 72, 41-54. [CrossRef]

4. Zhao, Y.; Liu, C.; Zhang, Y.; Yang, J.; Feng, T. Damaging behavior investigation of an operational tunnel structure induced by cavities around surrounding rocks. Eng. Fail. Anal. 2019, 99, 203-209. [CrossRef]

5. Zhang, Y.; Shi, Y.; Zhao, Y.; Yang, J. Damage in concrete lining of an operational tunnel. J. Perform. Constr. Facil. 2017, 31, 06017002. [CrossRef]

6. Feng, H.; Zhang, X.; Gou, D.; Chun, J.; Ou, X.; Zhou, X. Cause investigation of side-wall cracking in an operational tunnel. Eng. Fail. Anal. 2019, 101, 157-171. [CrossRef]

7. Xiao, J.; Dai, F.; Wei, Y.; Min, H.; Xu, C.; Tu, X.; Wang, M. Cracking mechanism of secondary lining for a shallow and asymmetrically-loaded tunnel in loose deposits. Tunn. Undergr. Space Technol. 2014, 43, 232-240. [CrossRef]

8. Jane, M.P.; David, C.; Ian, D.M.; Neil, H. Impact of soil erosion voids on reinforced concrete pipe responses to surface loads. Tunn. Undergr. Space Technol. 2018, 82, 111-124.

9. Do, N.A.; Oreste, P.; Dias, D.; Antonello, C.; Djeran-Maigre, I.; Livio, L. Stress and strain state in the segmental linings during mechanized tunnelling. Geomech. Eng. 2014, 7, 75-85. [CrossRef]

10. Zhang, X.; Zhang, C.; Min, B.; Xu, Y. Experimental study on the mechanical response and failure behavior of double-arch tunnels with cavities behind the liner. Geomech. Eng. 2020, 20, 399-410.

11. Meguid, M.A.; Dang, H.K. The effect of erosion voids on existing tunnel linings. Tunn. Undergr. Space Technol. 2009, 24, 278-286. [CrossRef]

12. Zhang, X.; Ye, Z.; Min, B.; Xu, Y. Effect of voids behind lining on the failure behavior of symmetrical double-arch tunnels. Symmetry 2019, 11, 1321. [CrossRef]

13. Yasuda, N.; Tsukada, K.; Asakura, T. Elastic solutions for circular tunnel with void behind lining. Tunn. Undergr. Space Technol. 2017, 70, 247-285. [CrossRef]

14. Fu, J.; Xie, J.; Wang, S.; Yang, J.; Yang, F.; Pu, H. Cracking performance of an operational tunnel lining due to local construction defects. Int. J. Geomech. 2019, 19, 04019019. [CrossRef]

15. Sedarat, H.; Kozak, A.; Hashash, Y.; Shamsabadi, K. Contact interface in seismic analysis of circular tunnels. Tunn. Undergr. Space Technol. 2009, 24, 482-490. [CrossRef]

16. Meguid, M.A.; Kamel, S. A three-dimensional analysis of the effects of erosion voids on rigid pipes. Tunn. Undergr. Space Technol. 2014, 43, 276-289. [CrossRef]

17. Chen, Z.; Jia, P. Three-dimensional analysis of effects of ground loss on static and seismic response of shafts. Tunn. Undergr. Space Technol. 2019, 92, 103067. [CrossRef]

18. Yasuda, N.; Tsukada, K.; Asakura, T. Three-dimensional seismic response of a cylindrical tunnel with voids behind the lining. Tunn. Undergr. Space Technol. 2019, 84, 399-412. [CrossRef]

19. Li, Y.; Luo, R.; Zhang, Q.; Xiao, G.; Zhou, L.; Zhang, Y. Model test and numerical simulation on the bearing mechanism of tunnel-type anchorage. Geomech. Eng. 2017, 12, 139-160. [CrossRef] 
20. Zhang, X.; Zhang, C.; Feng, G.; Han, K. Experimental studies on effect of voids behind tunnel linings on progressive failure process of tunnel structures. Chin. J. Geotech. Eng. 2017, 39, 1137-1144.

21. Leung, C.; Meguid, M.A. An experimental study of the effect of local contact loss on the earth pressure distribution on existing tunnel linings. Tunn. Undergr. Space Technol. 2011, 26, 139-145. [CrossRef]

22. Ye, Z.; Zhang, C.; Ye, Y. Model test of detection of contact status behind shield tunnel segment using the transient electromagnetic radar. J. China Railw. Soc. 2019, 41, 121-131.

23. Ye, Z.; Ye, Y. Comparison of detection effect of cavities behind shield tunnel segment using transient electromagnetic radar and ground penetration radar. Geotech. Geol. Eng. 2019, 37, 4391-4403. [CrossRef]

24. Lai, W.W.L.; Derobert, X.; Annan, P. A review of ground penetrating radar application in civil engineering: A 30-year journey from locating and testing to imaging and diagnosis. NDT E Int. 2018, 96, 58-78.

25. Ye, Z.; Zhang, C.; Ye, Y.; Zhu, W. Application of transient electromagnetic radar in quality evaluation of tunnel composite lining. Constr. Build. Mater. 2020, 240, 117958. [CrossRef]

26. Kravitz, B.; Mooney, M.; Karlovsek, J.; Danielson, I.; Hedayat, A. Void detection in two-component annulus grout behind a pre-cast segmental tunnel liner using ground penetrating radar. Tunn. Undergr. Space Technol. 2019, 83, 381-392. [CrossRef]

27. Ye, Z.; Ye, Y.; Zhang, C. Transient electromagnetic effect of the underdamped center loop. Prog. Geophys. 2019, 34, 2106-2111.

28. Li, W.; Zhang, C. Face stability analysis for a shield tunnel in anisotropic sands. Int. J. Geomech. 2020, 20, 04020043. [CrossRef]

29. Li, W.; Zhang, C.; Zhu, W.; Zhang, D. Upper-bound solutions for the face stability of a non-circular NATM tunnel in clays with a linearly increasing undrained shear strength with depth. Comput. Geotech. 2019, 114, 103136. [CrossRef]

30. Zhang, C.; Li, W.; Zhu, W.; Tan, Z. Face stability analysis of a shallow horseshoe-shaped shield tunnel in clay with a linearly increasing shear strength with depth. Tunn. Undergr. Space Technol. 2020, 97, 103291. [CrossRef]

31. Yang, X.; Yan, R. Collapse mechanism for deep tunnel subjected to seepage force in layered soils. Geomech. Eng. 2015, 8, 741-756. [CrossRef]

32. Zhang, C.; Han, K.; Zhang, D. Face stability analysis of shallow circular tunnels in cohesive-frictional soils. Tunn. Undergr. Space Technol. 2015, 50, 345-357. [CrossRef]

33. Zhang, D.; Zhang, S.; Fang, Q.; Chen, F. Study of contact state behind tunnel lining in process of railway operation and its analysis. Chin. J. Rock Mech. Eng. 2013, 32, 217-224.

34. Code for Design of Railway Tunnel (TB10003-2016); National Railway Administration: Bejing, China, 2016.

35. Park, J.K.; Hossain, S.; Oh, J.; Yoo, H.; Kim, H. Assessment of risk potential due to underground box structure installation employing ANN model and field experimental approaches. J. Perform. Constr. Facil. 2020, 34, 04020057. [CrossRef]

36. Wang, M.; Hu, Y.; Jiang, C.; Wang, Y.; Liu, D.; Tong, J. Mechanical characteristics of cement-based grouting material in high-geothermal tunnel. Materials 2020, 13, 1572. [CrossRef]

37. Yao, Y.; Ren, X.; Zhang, J. Analysis of impact of contact relationship between lining and surrounding rock on external water pressure in rich water areas. J. China Three Gorges Univ. 2015, 37, 52-55.

38. Yue, J.; Wei, Y.; An, Y. Research on lining mechanics properties of tunnel across river by shallow burried method. Highway 2017, 2, 224-229.

39. Min, B.; Zhang, C.; Zhang, X.; Wang, H.; Li, P.; Zhang, D. Cracking performance of asymmetric double-arch tunnels due to the voids behind linings. Thin-Walled Struct. 2020, 154, 106856. [CrossRef]

40. Peng, J.; Tang, C.A. Numerical study on failure mechanism of tunnel in jointed rock mass. Tunn. Undergr. Space Technol. 2008, 23, 500-507.

41. Liu, S.; Shi, Y.; Sun, R.; Yang, J. Damage behavior and maintenance design of tunnel lining based on numerical evaluation. Eng. Fail. Anal. 2019, 109, 104209. [CrossRef]

Publisher's Note: MDPI stays neutral with regard to jurisdictional claims in published maps and institutional affiliations. 